\title{
Adaptive drift and barrier-avoidance by a fly-forage migrant along a climate-driven flyway
}

Wouter M.G. Vansteelant ${ }^{1,2^{*}}$, Laura Gangoso ${ }^{1,3}$, Willem Bouten ${ }^{2}$, Duarte S. Viana ${ }^{4}$ and Jordi Figuerola ${ }^{1}$

\begin{abstract}
Background: Route choice and travel performance of fly-forage migrants are partly driven by large-scale habitat availability, but it remains unclear to what extent wind support through large-scale wind regimes moulds their migratory behaviour. We aimed to determine to what extent a trans-equatorial fly-forage migrant engages in adaptive drift through distinct wind regimes and biomes across Africa. The Inter-tropical Front (ITF) marks a strong and seasonally shifting climatic boundary at the thermal equator, and we assessed whether migratory detours were associated with this climatic feature. Furthermore, we sought to disentangle the influence of wind and biome on daily, regional and seasonal travel performance.
\end{abstract}

Methods: We GPS-tracked 19 adult Eleonora's falcons Falco eleonorae from the westernmost population on the Canary Islands across 39 autumn and 36 spring migrations to and from Madagascar. Tracks were annotated with wind data to assess the falcons' orientation behaviour and the wind support they achieved in each season and distinct biomes. We further tested whether falcon routes across the Sahel were correlated with the ITF position, and how realized wind support and biome affect daily travel times, distances and speeds.

Results: Changes in orientation behaviour across Africa's biomes were associated with changes in prevailing wind fields. Falcons realized higher wind support along their detours than was available along the shortest possible route by drifting through adverse autumn wind fields, but compromised wind support while detouring through supportive spring wind fields. Movements across the Sahel-Sudan zone were strongly associated to the ITF position in autumn, but were more individually variable in spring. Realized wind support was an important driver of daily travel speeds and distances, in conjunction with regional wind-independent variation in daily travel time budgets.

Conclusions: Although daily travel time budgets of falcons vary independently from wind, their daily travel performance is strongly affected by orientation-dependent wind support. Falcons thereby tend to drift to minimize or avoid headwinds through opposing wind fields and over ecological barriers, while compensating through weak or supportive wind fields and over hospitable biomes. The ITF may offer a climatic leading line to fly-forage migrants in terms of both flight and foraging conditions.

Keywords: Aeroecology, Biometeorology, Bird migration, Flight behaviour, Orientation, Weather

\footnotetext{
* Correspondence: wouter.vansteelant@ebd.csic.es

'Estación Biológica de Doñana, CSIC. Cartuja TA-10, Edificio I, Calle Américo

Vespucio, s/n, 41092 Sevilla, Spain

${ }^{2}$ Institute for Biodiversity and Ecosystem Dynamics (IBED), University of

Amsterdam, Sciencepark 904, 1098 XH Amsterdam, The Netherlands

Full list of author information is available at the end of the article
}

(c) The Author(s). 2021 Open Access This article is licensed under a Creative Commons Attribution 4.0 International License, which permits use, sharing, adaptation, distribution and reproduction in any medium or format, as long as you give appropriate credit to the original author(s) and the source, provide a link to the Creative Commons licence, and indicate if changes were made. The images or other third party material in this article are included in the article's Creative Commons licence, unless indicated otherwise in a credit line to the material. If material is not included in the article's Creative Commons licence and your intended use is not permitted by statutory regulation or exceeds the permitted use, you will need to obtain permission directly from the copyright holder. To view a copy of this licence, visit http://creativecommons.org/licenses/by/4.0/ The Creative Commons Public Domain Dedication waiver (http://creativecommons.org/publicdomain/zero/1.0/) applies to the data made available in this article, unless otherwise stated in a credit line to the data. 


\section{Introduction}

Migrating birds must negotiate highly variable as well as dynamic atmospheric conditions during their global wanderings. In many species, the routes of a single individual may lie hundreds if not thousands km's apart in consecutive years, despite migrant birds tend to return to the same location each year. Such route flexibility is likely adaptive, enabling birds to cope with annual variation in local weather conditions and resource availability [1-3]. Nevertheless, climatic conditions and prevailing winds change in a somewhat seasonally predictable manner across the globe. For example, while westerlies dominate the mid-latitudes, easterly trade winds prevail in the Hadley cells and converge at the Inter-tropical Convergence Zone (ITCZ) along the seasonally shifting thermal equator [4]. Because wind has a strong impact on flight costs [5] such prevailing winds and other persistent circulation patterns can create reliable freeways as well as persistent blockades for aerial migrants at regional to continental scales [6-10]. Studies integrating biologging data with atmospheric models generally reveal some alignment of seasonal loop migrations with prevailing winds across marine [11-13] as well as terrestrial environments [14-17]. For landbirds this is especially true over ecological barriers - where exhaustion from battling adverse winds can have lethal consequences [18-20]. Furthermore, it is expected that birds tolerate more drift in the early stages of their migration, and increasingly (over) compensate for the incurred drift as they approach their destination [6, 7]. However, birds can theoretically engage in adaptive drift anywhere along the flyway, minimizing transport costs by (partially) drifting in strong and opposing winds, and (over) compensating for previously incurred (or 'anticipated') drift in areas with weak or following winds [7, 15, 21].

In the context of trans-African migration, the InterTropical Front (ITF) marks a particularly sharp boundary between seasonal climates along the thermal equator, which moves northward during the spring migration, and southward during the autumn migration [22-24]. This boundary is often also called the ITCZ. However, the ITF which occurs over continental Africa is structurally distinct from the ITCZ which occurs over the ocean $[22,23]$. The ITF marks the separation between areas under the influence of strong and dry north-easterly desert winds (the so-called Harmattan) and weaker and humid monsoon flows coming from the Atlantic and Indian Ocean, and like the ITCZ, the ITF is characterized by weak horizontal winds. However, while the main band of convective precipitation coincides with the ITCZ over the ocean, the northern limit of the monsoon rain belt lags some $100-250 \mathrm{~km}$ south of the ITF during its northward advance in spring [24]. These monsoon dynamics are key drivers of vegetation growth and the emergence of insect prey for migrant birds in Africa's savannas, and various authors have pointed to the significance of the seasonally shifting ITF for trans-African migrants [25, 26]. Yet to our knowledge no studies have empirically tested how the ITF affects route choice of migrant birds in Africa, and still few migration studies have explicitly assessed trans-African migration routes in the context of large-scale seasonal wind regimes (but see [10] and references therein).

In this study, we assess how prevailing winds around the thermal equator and across distinct biomes mould trans-equatorial migration routes and performance patterns of Eleonora's Falcons Falco eleonorae, a fly-forage migrant that exhibits great flexibility in route choice and performance across Africa. The picture emerging from over a decade of tracking studies across the Mediterranean breeding range of Eleonora's falcons is that of an increasingly pronounced zig-zag autumn migration pattern towards more western populations. Adults thereby depart in a south- to southeast direction towards Madagascar from their respective colonies, turning to the southwest over the Sahara, and reorienting to Madagascar after reaching vegetated areas in the Sahel [27-31]. In spring, adults from all colonies tend to return along a more eastern, and in most cases shorter route, with most individuals using stop-over sites to the south and east of the Ethiopian Highlands, in the Horn of Africa. This seasonal loop migration pattern occurs in part because Eleonora's falcons minimize the distance flown over sea via the Mozambique Channel in opposing autumn winds, while making ocean-crossings in excess of $1000 \mathrm{~km}$ from northern Madagascar to East Africa in supportive spring winds [29-32]. However, route choice has rarely been studied in the context of the wind support that is available across the entire flyway [31], and studies that tested the effect of experienced wind conditions on daily and seasonal performance have yielded contradictory results $[29,33]$. This may be due to the confounding influence of ecological barrier effects and foraging opportunities across different biomes. Indeed, biomes are likely to be characterized by distinct climatic conditions and wind regimes. However, the relative importance of landscape and wind in shaping falcon routes and performance -and of fly-forage migrants more generally- remains unclear.

Our study population is situated at the western limit of the species' range, so that falcons must cross the entire breadth of Africa to and from their Malagasy wintering grounds [34]. This makes Canarian Eleonora's falcons an ideal model to study the response of a transequatorial fly-forage migrant to the shifting position of the ITF, and determine to what extent adaptive drift through prevailing winds shapes their seasonal route 
choice and performance across multiple biomes. Based on the adaptive drift framework, we expect Eleonora's falcons to deviate from the shortest possible route (i.e., the great-circle route GCR) by (over) drifting through areas with strong prevailing winds, especially when those winds oppose migration along the GCR, or when they coincide with ecological barriers, as these would be strong motivations to maximize local wind support. By contrast, we expect falcons to follow the GCR or to overcompensate for previous or anticipated displacements through supportive or weak prevailing winds. We specifically expect major course and performance changes at the ITF, which is located over the SahelSudan climate zone, and which we expect to mark the southern limit of the desert barrier in both seasons. Based on previous studies in other colonies we also expect falcons to detour to stop-over areas in the Horn of Africa independently from wind, and to make a relatively direct return to their summer range, resulting in a shorter spring than autumn migration. Finally, we expect that wind support along the falcons' realized routes to be an important driver of daily, regional and seasonal performance, in addition to landscape differences in daily travel time budgets.

\section{Methods}

\section{Tracking falcons}

During the breeding seasons of 2012, 2014, 2017 and 2018 a total of 40 Eleonora's falcons were equipped with UvA-BiTS GPS-trackers (7.5 g) [35] on Alegranza islet $\left(29^{\circ} 24^{\prime} \mathrm{N}, 13^{\circ} 30^{\prime} \mathrm{W}, 1050\right.$ ha, $\max 289 \mathrm{~m}$ a.s.l.). This is the northernmost islet of the Chinijo Archipelago in the Canary Islands, $160-300 \mathrm{~km}$ west off the African coast (Fig. 1a). The Eleonora's falcon colony on Alegranza consists of an average of 127 breeding pairs, about $45 \%$ of the Canarian breeding population [36, 37], and is located at the western limit of the species' breeding range.

Falcons were tagged with GPS attached as backpacks [38] using $6.35 \mathrm{~mm}$ wide Teflon harnesses. In total the device and harness weighed $\sim 8 \mathrm{~g}$, equivalent to $2.03-$ $2.63 \%$ and $1.61-2.42 \%$ of the mass at capture for male $(304-395 \mathrm{~g})$ and female $(330-495 \mathrm{~g})$ falcons, respectively. During the non-breeding season, geographical positions were recorded at intervals ranging from minutes to hours (depending on solar-dependent battery power and different measurement schemes between night and day, and between migration and 'wintering' areas) with a horizontal precision of 3-15 m. Migration data were downloaded through a local antenna network every summer (July-October) between 2013 and 2020. We were able to download migration data for 19 individuals (10 males, 9 females, Table S1).

We are certain that at least 7 of the 21 individuals for which we were unable to retrieve data did return to the archipelago, but bred out of reach of the antenna network (i.e. on other islets, or shaded by steep cliffs). In addition, one tracker was detached soon after deployment and two others failed to communicate and did not download data. Such issues likely impaired data retrieval for several more individuals. These issues complicate assessment of tag effects. All considered, however, at least $72.5 \%$ of tagged birds returned to the Canary Islands at least once, and 13 falcons were tracked across two or more migrations (Table S1), and mostly successful breeding attempts, suggesting a limited impact of tagging on falcons' migration and breeding performance.

\section{Defining migratory movements}

To extract migration data, we defined the start and end of the wintering period as the first and last date a bird was recorded in Madagascar during each non-breeding cycle. The start and end of the breeding season are more difficult to define because Eleonora's falcons engage in wide-ranging pre-breeding movements, scattering across staging areas up to hundreds of km's from their breeding site [39]. Analogously, falcons often stopped-over in northwest Africa before initiating their autumn flight towards Madagascar. While such pre- and post-breeding periods form an integral part of avian migrations, and migratory fuelling strategies in particular [40], the focus of this study is on large-scale orientation behaviour and its consequences for realized wind support and travel performance. We thus excluded pre- and post-breeding movements for our analyses, taking the day on which falcons left the Western Sahara or Morocco as the start of autumn migration (Fig. 1a, b). We took the first stopover day (i.e. days with $<100 \mathrm{~km}$ travelled between the first and last fix) in Western Sahara or Morocco, or the day on which falcons first reached the Atlantic Ocean, as the end date for spring migration. Two spring trips were only partially recorded and excluded from further analyses (B1014 in 2015, B2337 in 2018). In total, we retained 1,041,854 positions covering a total of 39 autumn and 36 spring migrations by 19 falcons (Table S1).

\section{Resampling and movement statistics}

To couple movement data with global atmospheric reanalysis models $[10,41]$ we standardized the temporal resolution of the movement data to hourly intervals. Our resampling procedure allowed for deviations up to $10 \mathrm{~min}$ from an hourly interval. The resampled dataset comprised 49,314 locations covering 2294 bird days. Movement statistics (direction, step length, duration and speed) were calculated from each resampled fix to the next. To distinguish directed movements (i.e. travel) from localized foraging/resting we used an hourly speed threshold of 


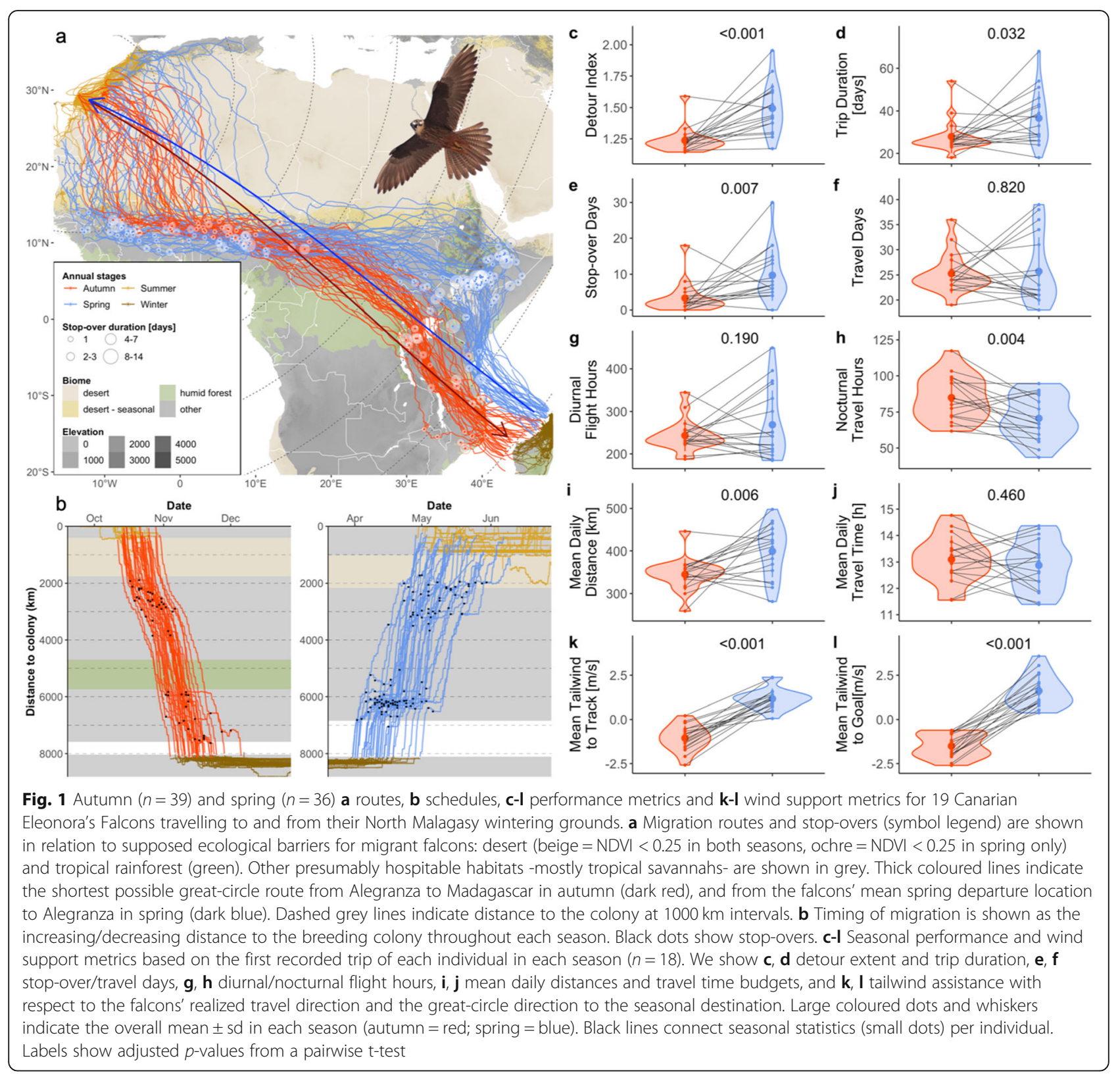

$5 \mathrm{~km} \mathrm{~h}^{-1}$. For each day we then calculated the total amount of travel time by summing the duration of all travel segments. Because falcons can migrate by night as well as by day (Fig. S1) we also determined the diurnal and nocturnal number of hours spent travelling, and calculated daily beeline distances (hereinafter: daily distances) as the great-circle (i.e. orthodromic) distance from the first to the last fix on each day. The mean daily travel speed was determined as the average trajectory speed across all travel segments (thus excluding intermittent foraging and resting events from travel speed calculations).

\section{Route segmentation: travel vs. stop-over days}

Because Eleonora's falcons are fly-forage migrants $[31,33]$ it is not easy to distinguish active travel from stop-overs. After inspecting frequency distributions of various movement statistics, we defined stop-over days as days on which birds achieved a daily beeline distance $<100 \mathrm{~km}$. This classification is supported by marked differences in daily travel time budgets between rest and travel days (Fig. S1). According to our classification 39,694 locations were recorded on 1842 travel days, and 9620 locations on 452 stop-over days. We then segmented trips into 
periods of continuous travel and resting, and then calculated the total duration and mean longitude and latitude of each stop-over event $(n=175$, duration: 1-14 days).

\section{Route annotation: biomes}

Because falcons likely adjust orientation behaviour and performance to ecological barriers and foraging opportunities [28, 33] we distinguished between four biome categories, including two 'hard' ecological barriers (Sahara desert, Indian Ocean), a presumed 'soft' ecological barrier for falcons (i.e. the tropical humid forest of the Congo Basin) and lumping all other biomes (mostly tropical savannahs along the falcons' routes) as 'hospitable landscapes' (Fig. 1a, b; Fig. S2). We included fixes over islands in sea-crossings. The boundaries of the tropical humid forest were extracted from a static global biome map [42] whereby we annotated flights over the Congo Basin as forest-crossing events (i.e. excluding flights over small forest patches in East Africa, Fig. S2). The barren 'desert' landscape of the Sahara is known to extend further south into the Sahel-Sudan zone during spring (start of wet season) compared to autumn (end of wet season). Therefore, we constructed Maximum-PixelValue composite maps of seasonal NDVI from the MODIS 16-day NDVI product (MCD43A4 V6, $500 \times 500 \mathrm{~m})$ [43] in Google Earth Engine [44]. We thereby considered all NDVI data between the mean seasonal start and end date of migration for each year between 2012 and 2020 (Additional file 3). Pixels with a maximum seasonal NDVI $<0.25$ were considered as 'desert', because it has been suggested that falcons avoid areas under this threshold [30]. We then annotated Sahara-crossings as the longest continuous desertcrossing on each trip (Fig. S2). Daily biome values were calculated as the modal biome value on each bird day.

\section{Route annotation: wind support and orientation}

We used the RNCEP package [45] to annotate all GPSfixes recorded on travel days with $\mathrm{u}$ - and $\mathrm{v}$-wind components as estimated at the $850 \mathrm{mb}$ pressure level $(\sim 1170$ $1590 \mathrm{~m}$ asl) in the NOAA-NCEP Reanalysis II model [46], corresponding to a mean flight altitude of $1344 \pm$ $880 \mathrm{~m}$ asl in our resampled dataset. Wind estimates were tri-linearly interpolated in time and space from 6-hourly model data with a horizontal resolution of $2.5^{\circ} \times 2.5^{\circ}$. From these wind components we derived wind speed and direction at each location, which we used to calculate the strength of tail-/headwinds and sidewinds relative to (i) the realized travel direction (i.e. direction from $t_{i}$ to $t_{i+1}$ ) and (ii) to the shortest possible GCR from $t_{i}$ to the seasonal goal destination. To simulate the shortest possible route we used the geosphere package [47] to determine the nearest point on the island of Madagascar from each point along the autumn route. We used the centre of Alegranza islet $\left(29^{\circ} 24^{\prime} \mathrm{N}, 13^{\circ} 30^{\prime} \mathrm{W}\right)$ as the intended spring destination. To obtain daily estimates of wind support we averaged hourly tailwind and sidewind strength relative to the realized and great-circle travel direction across all travel segments on each travel day.

In order to determine when and where falcons improved tailwind assistance by deviating from the GCR we calculated a Local Wind Gain Index (LWGI) as:

$$
L W G I=\frac{W * \cos (\theta)-W * \cos (\beta)}{W}
$$

whereby $\mathrm{W}$ represents total wind speed, $\theta$ represents the angle between the direction of the wind and the birds travel direction, and $\beta$ represents the angle between the direction of the wind and the GCR to the seasonal destination. If LWGI $=0$ then the bird is following the GCR (i.e. $\theta=\beta$ ). If winds blow in the same direction this would be the optimal situation from an energyminimizing perspective. If $\mathrm{LWGI}=1$ then a bird has gained the equivalent of the total prevailing wind speed by deviating from the GCR. This can happen, for example, if the wind blows perpendicular to the GCR while providing a pure tailwind along the birds' chosen direction (i.e. $\theta=0, \beta=90^{\circ}$ ). The highest possible value of $\mathrm{LWGI}=2$, and occurs if the prevailing winds provide a pure tailwind in the chosen direction, but a pure headwind along the GCR (i.e. $\theta=0, \beta=180^{\circ}$ ). Conversely, $2<$ LGWI $<0$ indicate situations where a bird experiences less wind support along its chosen route vs. the GCR.

We further classified orientation responses to sidewinds from the ratio between the falcons' sideward displacement rate and the sidewind strength relative to the GCR, distinguishing between overcompensation (ratio < $-0.2)$, full compensation $(-0.2<$ ratio $<0.2)$, partial compensation $(0.2<$ ratio $<0.8)$, full drift $(0.8<$ ratio $<$ 1.2 ), overdrift (ratio $>1.2$ ), and cases with no/weak sidewinds (sidewind strength $<0.5 \mathrm{~ms}^{-1}$ ) $[14,15,48]$. Overcompensation is thus expected to compromise local wind support (i.e. LWGI < 0 ) compared to the GCR (i.e. compensation), whereas partial compensation and (over) drift are expected to result in local wind support gains (i.e. LGWI > 0).

\section{Route contextualisation: ITF, climate and wind fields}

We obtained decadal positional estimates for the ITF from the NOAA Climate Prediction Center - West African Monsoon Monitoring project (https://www.cpc. ncep.noaa.gov/products/international/itf/itcz.shtml).

This data product consists of latitudinal estimates of the ITF at intervals of $5^{\circ}$ longitude between $10^{\circ} \mathrm{W}$ to $35^{\circ} \mathrm{E}$, and from April through October each year (coinciding 
with the West African monsoon, but unfortunately do not include information for the second half of the autumn migration in November). The positional estimates are based on a subjective interpretation of (i) surface dewpoint temperature and (ii) lower-level (i.e. 925mb) wind fields by expert meteorologists. For visualization purposes we mapped the mean and inter-quartile latitude (Q25\%-Q75\%) of the ITF in October and April for autumn and spring, respectively.

Next, we used the RNCEP package [45] to visualize synoptic wind fields and seasonal rainfall during our study period. To do this we downloaded wind estimates relative to the $850 \mathrm{mb}$ pressure level and precipitation rates relative to a gaussian grid from the NOAA-NCEP Reanalysis II model [46]. We downloaded data for the entire migratory domain (as defined by the min and max longitude and latitude recorded on migration) and for the months of April and October throughout the study period (autumn 2012 - spring 2020). To visualize prevailing atmospheric flows, we averaged $\mathrm{u}$ - and $\mathrm{v}$ components for each node in the NCEP model grid across the entire study period. To visualize seasonal rainfall, we converted precipitation rate estimates $(\mathrm{mm}$ $\mathrm{m}^{-2} \mathrm{~s}^{-1}$ ) to total precipitation estimates $(\mathrm{mm})$ for each six-hour interval in the NCEP model. We then integrated these values across each month, and finally averaged monthly rainfall estimates at each node in the NCEP-grid across the study period, for April and October respectively.

In addition, to visualize the timing of migratory movements in relation to the timing of ITF and climatic shifts, we superimposed falcon data on a Hovmöller diagram for mean daily rainfall across mainland Africa - a common approach to display 'waves' in meteorological data. To do this, RNCEP rainfall data were integrated to daily rainfall estimates at every node in the NCEP grid. For each day of the year we then averaged daily rainfall estimates across each band of $2.5^{\circ}$ latitude and all years in the study period.

\section{Statistical analyses}

\section{Seasonal detours and performance patterns}

We determined the extent of seasonal detours as the ratio of the cumulative distance travelled across all travel segments on travel days over the great-circle distance from the first to the last GPS-fix on each trip. Next, we calculated the total duration, number of stop-over and travel days, total number of nocturnal and diurnal travel hours, average daily distance, average daily travel time, average daily mean travel speed and average daily mean tailwind assistance (relative to the realized route and the GCR) for each trip. Using paired two-sided t-tests we then tested for seasonal differences in each of these performance and wind assistance metrics, using the first recorded trip for each individual in each season. These pairwise tests excluded one individual for which we lacked spring migration data (B2337, Table S1).

Next, we used generalized linear mixed regression models (GLMMs) to test if trip duration, rest/travel days and tailwinds were associated with detour extent, and whether this association differed between seasons $(n=75$ trips). All response variables were fitted assuming a Gaussian error distribution and identity link function. The response variables trip duration, travel days and rest days were skewed positively and were log-transformed. For each response variable we compared models including additive and interaction effects of detour extent and season. We further allowed for random variation in intercepts between individuals and years to account for individual variability in behaviour and repeated sampling of the same individuals (number of trips recorded per season varied from 1 to 4 between individuals), and to account for repeated measurements within years. We calculated Aikaike's Information Criterion corrected for small sample sizes (AICc) and AICc weights, and used the rsq package [49] to determine the coefficient of determination $\left(R^{2}\right)$ of each model and the partial $R^{2}$ values for fixed and random terms, respectively, using the rsq package [49]. We then calculated deltaAICc as the difference in AICc values between each model and the model with the lowest AICc value. The best model for each response variable was identified as the most parsimonious model within those ranked with $\triangle \mathrm{AICc}<2$ (further corroborated by AICc weights), after which the lmerTest package was used to obtain $p$-values for fixed effects using Satterthwaite's method [50].

\section{Route choice in relation to the ITF}

We aimed to test the relationship between ITF latitudinal position and the latitude at which falcons crossed the Sahel-Sudan climate zone. We extracted migration data for that stage of the trip by selecting all fixes between $17.5^{\circ} \mathrm{W}-37.5^{\circ} \mathrm{E}$ and between $5^{\circ} \mathrm{N}$ $15^{\circ} \mathrm{N}$ on travel days where the daily travel direction was oriented due east in autumn $\left(65^{\circ}<\operatorname{dir}<125^{\circ}\right)$ or due west in spring $\left(-125^{\circ}>\operatorname{dir}>-65^{\circ}\right)$. ITF latitudinal position estimates are provided every 10 days and for every five degrees longitude, and so we averaged the falcons' latitudinal position across corresponding spatiotemporal blocks $(n=293)$. Finally, we used GLMMs to test the effects of the ITF latitudinal position, season, longitude, their additive and interaction effects on the latitude of trans-Sahelian movements, allowing for randomly varying intercepts between individuals. The most parsimonious model within those ranked with $\triangle$ AICc $<2$ was considered the best model. 


\section{Daily performance vs. biome and wind conditions}

To help determine candidate models for an exhaustive model selection procedure, we first explored seasonal relationships of daily performance with biome and wind assistance variables, and the extent of individual variation in daily performance metrics. We used GLMMs to test (1) how daily travel time, biome and season (fixed effects) affected daily distance and daily mean travel speed, and to test (2) how daily mean head-/tailwinds, biome and season (fixed effects) affected daily travel time, daily distances and daily mean hourly speeds (building separate models for head-/tailwinds along the realized route and the simulated GCR). The response variables daily distance and daily mean speed were positively skewed and log-transformed. All models included randomly varying intercepts between individuals and years. The large sample of travel days $(n=1842)$ allowed to use $\triangle \mathrm{AIC}$ rather than $\triangle \mathrm{AICc}$ to identify the most parsimonious models. Additionally, we calculated the full $\mathrm{R}^{2}$ of each model, and the partial $\mathrm{R}^{2}$ for fixed and random terms.

Based on insights from simple models, we constructed a larger set of GLMMs to better understand variation in daily distances and daily mean travel speeds. Candidate models included: head/tailwind and absolute sidewind strength experienced along the realized route, daily travel time, biome, season, their additive effects, interaction effects of wind variables with daily travel time, biome and season, and an interaction effect of daily travel time with biome and season as fixed effects.

All data analyses and visualization was conducted in $R$ v.3.5.3 [51]. Graphs and maps were produced with ggplot2 [52].

\section{Results}

\section{General route description}

Eleonora's falcons initiated their autumn migration from the Canary Islands in the second half of October and completed the trip during the first 3 weeks of November (Fig. 1a-b, Table S1). They departed in a southeast direction but usually changed course more southward at some point across the Sahara, and maintained this direction until deep into the savannahs of the Sahel-Sudan zone (Fig. 1a). There, falcons abruptly changed direction eastward in a relatively narrow migration corridor, making irregular stop-overs. When they reached the point where they would have completed the desert-crossing had they followed the GCR from Alegranza to Madagascar, some falcons changed course southeast and directly crossed the tropical rainforest of the Congo Basin roughly along the GCR. However, more commonly falcons continued over the Sahel for another 500-1500 $\mathrm{km}$ before reorienting southeast, skirting the northeast corner of the Congo Basin and reaching the East African savannahs between Lake Victoria and the northernmost point of Lake Tanganyika. There they maintained a more southward direction and made irregular stop-overs before finally orienting east-southeast across the Mozambique Channel near its narrowest $420 \mathrm{~km}$ point.

The falcons departed on spring migration in the first half of April and reached their pre-breeding sites mostly in the first half of May (Fig. 1b, Table S1). In spring, falcons displayed an even more pronounced zig-zag migration pattern than in autumn (Fig. 1a). Upon leaving northern Madagascar falcons roughly followed the GCR to Alegranza, during an $800-1500 \mathrm{~km}$ flight across the Indian Ocean. Upon reaching East Africa they detoured northward to stop-over sites that were clustered to the south and east of the Ethiopian Highlands, although some individuals took a more direct route, making stopovers in Uganda and South Sudan. Thereafter, falcons did not return to Alegranza directly from East Africa, but instead travelled due west across the Sahel-Sudan zone for $2500-4000 \mathrm{~km}$, postponing the desert-crossing far beyond the point where they would have reached desert if they had followed the GCR directly from Madagascar (Fig. 1a). Falcons then frequently stoppedover in the West African Sahel, in areas slightly further south than where they stop-over in autumn, before making the desert-crossing (Fig. 1a).

\section{Seasonal detours, performance and wind support}

On average, Eleonora's falcons travelled $1606 \mathrm{~km}$ more in spring $(11,170 \pm 1220 \mathrm{~km})$ than in autumn $(9564 \pm$ $1220 \mathrm{~km}$, Table S1). The seasonal detours thus equated to 1.44 and 1.23 times the length of the GCR between their start and end locations $(\sim 7800 \mathrm{~km})$ in autumn and spring, respectively (Fig. 1a, c; Table S1). On average they needed 7 more days to complete their more detoured spring migration ( $34 \pm 10$ days) than their autumn migration $(27 \pm 6$ days, Fig. $1 d)$. However, this difference was largely due to falcons making about 6 more stop-over days in spring ( $9 \pm 6$ days) than in autumn (3 \pm 3 days, Fig. 1e). Despite the large difference in cumulative travel distance between seasons, we found no significant difference in travel days between autumn (25 \pm 3 days) and spring ( $24 \pm 6$ days, Fig. 1f). Males and females showed very similar patterns in overall performance within and between season (Table S2).

Falcons travelled for a similar amount of daylight hours in autumn $(241 \pm 34 \mathrm{~h})$ and spring $(250 \pm 67 \mathrm{~h}$, Fig. $1 \mathrm{~g})$, and slightly more hours at night during autumn $(85 \pm 13 \mathrm{~h})$ than spring $(71 \pm 13 \mathrm{~h}$, Fig. $1 \mathrm{~h})$. However, on average, there was no significant difference in daily travel time budgets between seasons (autumn: $13 \pm 1 \mathrm{~h}$, spring: $13 \pm 2 \mathrm{~h}$ ) (Fig. 1j). Falcons did achieve significantly greater daily distances during spring $(412 \pm 64 \mathrm{~km})$ than during autumn $(352 \pm 36 \mathrm{~km}) \quad$ (Fig. 1i), which was 


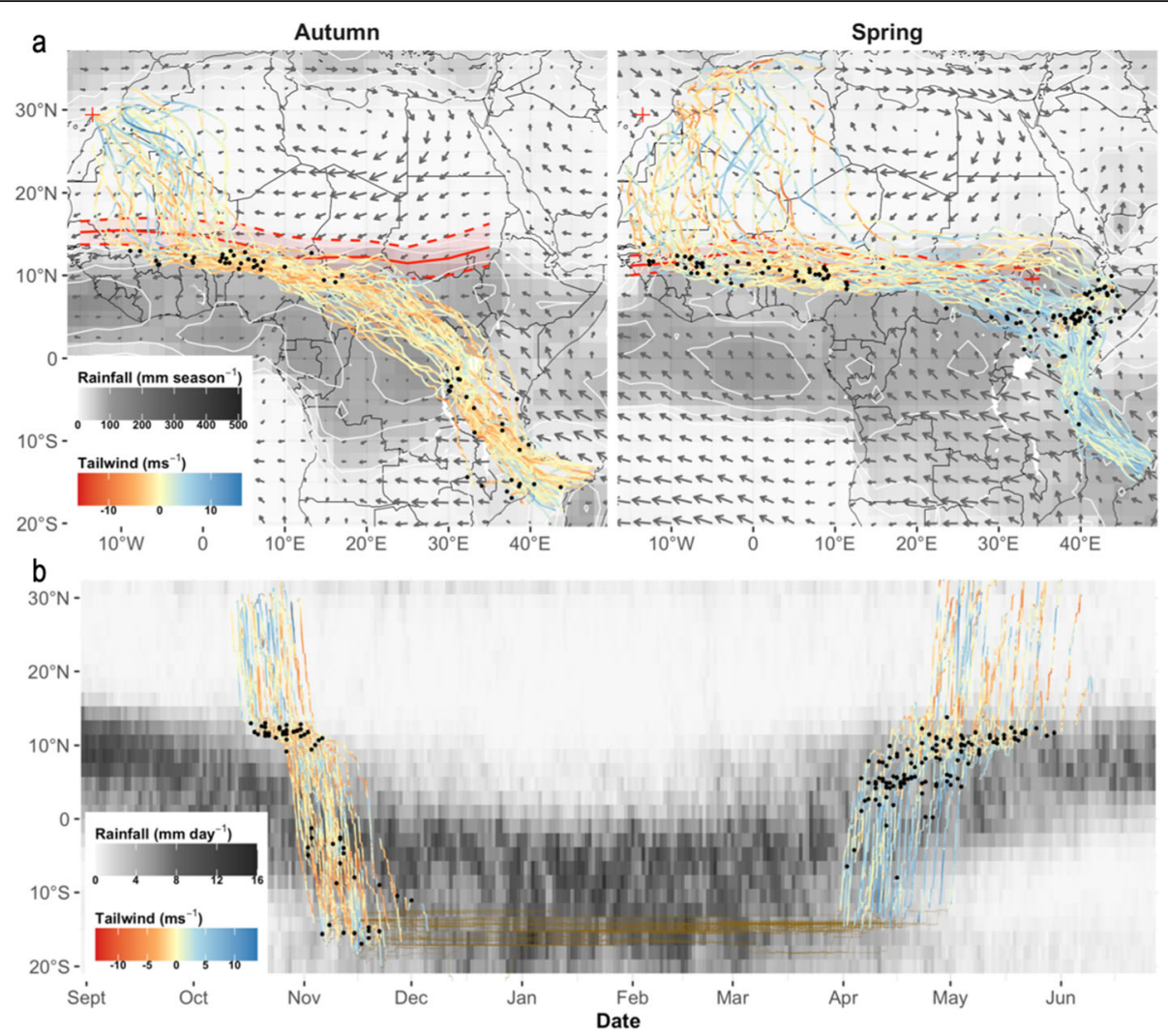

Fig. 2 Eleonora's falcon migration routes and timing relative to the seasonal position of the ITF and African rainfall. a Tracks are coloured according to tailwind strength along the falcons' realized travel direction (reds = headwinds, blues = tailwinds). Red ribbons show the mean latitudinal position (solid line) and Q10\%-Q90\% latitudinal range (dashed lines) of the ITF at each $5^{\circ}$ longitude. Note that ITF positions and rainfall heatmaps are based on data for October and April, which is representative for the period in which falcons initiate eastward/westward movements along the ITF in autumn/ spring, respectively. The ITF would have shifted further south/north by the time falcons crossed the Congo Basin in autumn and by the time they reached West Africa in spring, respectively. $\mathbf{b}$ Falcon tracks superimposed on a Hovmöller diagram for mean daily rainfall at every $2.5^{\circ}$ latitude across mainland Africa, visualizing the seasonal shift in rainfall latitude across Africa associated to the shifting position of the ITF

associated with a large seasonal difference in mean daily tailwind assistance: falcons generally experienced headwinds along their autumn routes $\left(-1.1 \pm 0.7 \mathrm{~ms}^{-1}\right)$ while benefiting from tailwinds along their spring routes (1.1 $\mathrm{ms}^{-1}$ ) (Fig. 1k). There was an even greater seasonal difference in wind support along the GCR, with autumn headwinds $\left(-1.6 \pm 0.7 \mathrm{~ms}^{-1}\right)$ and spring tailwinds $(1.7 \pm$ $0.9 \mathrm{~ms}^{-1}$ ) being more pronounced along the GCR than along the realized route (Fig. 1k-1).

Plotting linear relationships suggested a strong correlation of mean individual trip duration, stop-over days and travel days with detour extent per season, but not so for realized tailwind support (Fig. S3). GLMMs across all trips $(n=75)$ confirmed that seasonal differences in overall trip duration are accounted for by seasonal differences in detour extent (Table S3). However, variation in stop-over and travel days was best explained by the additive effect of season and detour extent (Fig. S3, Table S3). That is: rest days and travel days both significantly increased with detour extent, but falcons made significantly more stop-over days and needed fewer travel days to complete detours of comparable extent in spring than in autumn. Furthermore, mixed models showed that very little variation in trip duration and travel days could be attributed to individual or year differences (Table S3). However, random effects did account for $\sim 12 \%$ of variation in stop-over days (Table S3), and detailed regression outputs showed this effect was driven by individual differences in stop-over time budgets during spring migration.

Although we did not find a significant correlation of realized tailwind with detour extent based on average individual metrics (Fig. S3, Table S3) the best model based on all trips does suggest a negative interaction effect of season and detour extent on realized tailwinds (Tables S3-S4). However, this interaction explains little variation in addition to the $75 \%$ of variation already explained by a model including only season as fixed predictor (Table 

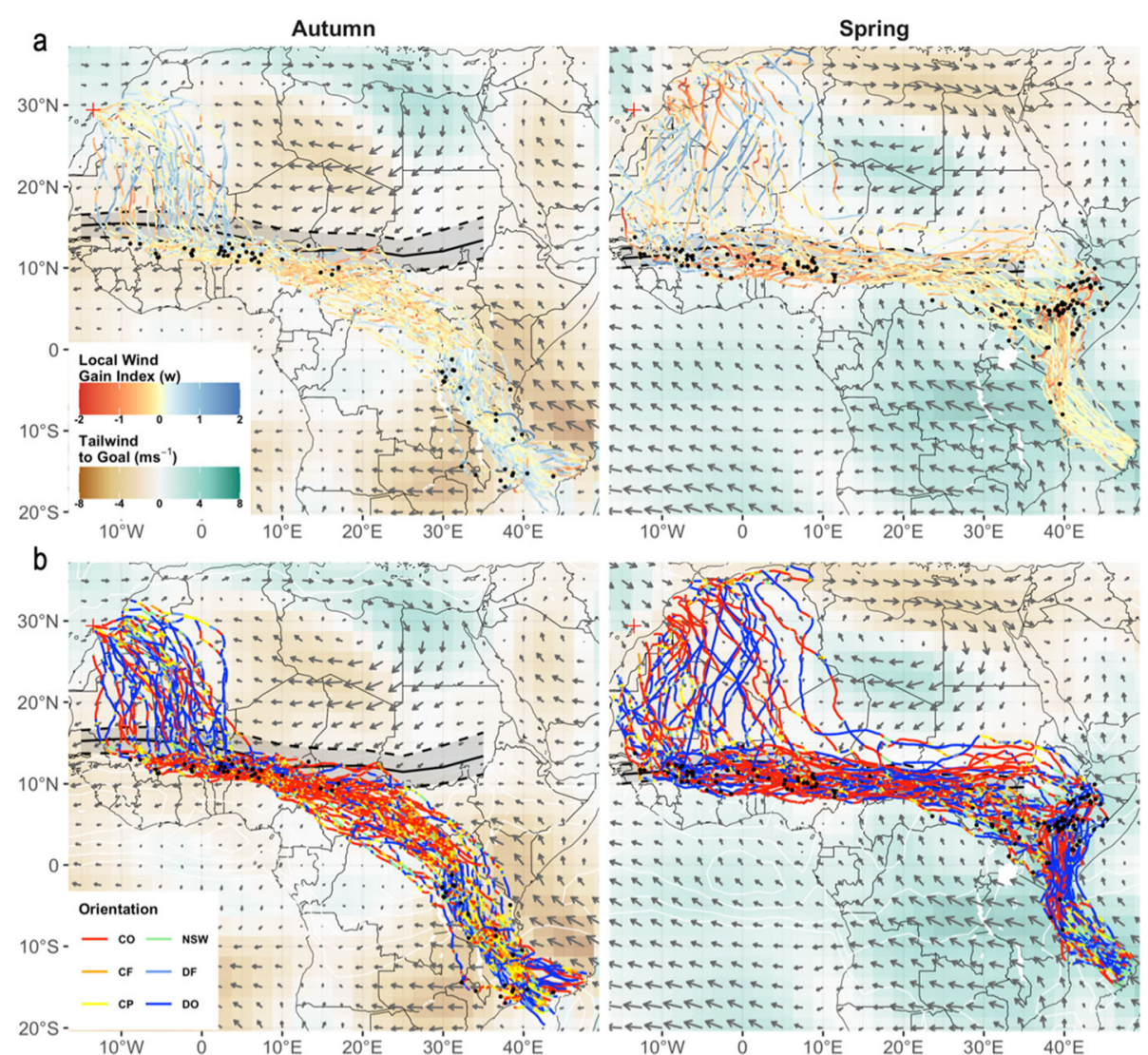

Fig. 3 Wind support gains and orientation responses of Eleonora's falcons to sidewinds through Africa's prevailing wind regimes. Black ribbons show the seasonal position of the ITF (cf. red ribbons Fig. 2). The heatmap indicates mean wind support along the GCR to the seasonal destination from each node in the wind data (browns = opposing winds, greens = supportive winds, white = perpendicular winds). We determined whether the tailwinds experienced by falcons along their detours represent (a) gains/losses in wind support compared to what was available along the GCR (reds = losses, blues = gains). b Orientation responses were classified as over-drift (DO, i.e. heading downwind from the $\mathrm{GCR}$ ), full drift (DF), partial (CP) or full compensatation (CF, i.e. staying on the GCR through sidewinds), overcompensation (CO, i.e. heading upwind the GCR). Cases where falcons stayed on the GCR in absence of sidewinds were not classified (NSW)

S3). The partial $\mathrm{R}^{2}$ for random model terms further showed that variability in wind support was not driven by individual or year differences (Table S3).

\section{Realized wind support and orientation through seasonal climates and wind fields}

Large-scale changes in orientation behaviour across Africa's biomes were associated with strong changes in seasonal climate and prevailing wind fields (Figs. 2-3, Fig. S4). In autumn, falcons experienced weak to moderately supportive tailwinds upon departure, but often also moderate headwinds further over the Sahara, until they crossed the ITF (Fig. 2a: blue line colour indicates supportive tailwinds along the realized track). Nevertheless, the southward course change over the Sahara was due to falcons overdrifting (Fig. 3b, Fig. S4), and thus associated with a substantial gain in wind support (i.e. a reduction in headwinds) through the GCR-opposing winds north of the ITF (Fig. 3a: blue tracks indicate gains in wind support). After the abrupt eastward course change (and stop-overs) south of the ITF, falcons overcompensated to track the northern front of the African rainbelt (Fig. $2 \mathrm{a}, \mathrm{b}$ ) and experienced moderate headwinds in doing so (Fig. 2a). Their tortuous fly-forage migration yielded a more irregular picture of wind gains/losses, but they incurred clear and increasingly large losses in wind support by continuing east of the GCR, and further on while crossing the tropical rainforest belt (Fig. 3a). That said, in absolute terms they faced only weak headwinds in these regions compared to what they would have experienced by tracking the GCR over the desert (Fig. 2a). After crossing the equatorial rain forest the falcons entered stronger, opposing wind fields once again, and realized a substantial headwind reduction by overdrifting and partially compensating for sidewinds across East Africa (Fig. 3b, Fig. S4). They finally crossed the Mozambique Channel without strong wind support -sometimes even headwinds (Fig. 3a)-, but still improved 
wind support compared to the GCR by (over) drifting in many cases (Fig. 3b).

In spring, the direct ocean-crossing to East Africa was associated with strong tailwind support due to prevailing south-easterlies (Fig. 2a). Note that this translated to a near-zero wind gain due to falcons' travel direction being closely aligned with the GCR here (note category NSW in Fig. 3a, b; Fig. S4). Nevertheless, relatively slight deviations from the GCR are often classified as overdrift over the Indian Ocean because winds are particularly strong there, and so our $0.5 \mathrm{~ms}^{-1}$ threshold for "no sidewinds" is frequently exceeded this region (Fig. $3 \mathrm{~b}$ ). The falcons continued to enjoy strong tailwind support as they detoured northward across mainland Africa (Fig. 2a), but in so doing they did not take full advantage of the available wind support along the GCR (Fig. 3b). In fact, for most of the overland spring migration falcons displayed a mixed pattern of both overdrift and overcompensation behaviours (Fig. 3b, Fig. S4).
Falcons that stopped-over in eastern Ethiopia and Somalia tended to depart in a northwest direction towards the desert, thereby overshooting the ITF, and then reoriented west-southwest in face of strong sidewinds over the eastern Sahara. All falcons travelled due west for at least several thousand $\mathrm{km}$ in a relatively narrow corridor that overlapped with the average position of the ITF during our study period (Fig. 2a), and stopping well south of the northern rain front in spring (Fig. 2b). They seemingly postponed the desert-crossing until West Africa, thereby tolerating a relatively large loss in local wind support compared to a more direct return (Fig. 3a). However, at worst this translates to a weak headwind near the ITF (Fig. 2a). Realized tailwinds over the desert appear highly variable (Fig. 2a) but falcons generally reduced headwind resistance by detouring from the GCR across the Sahara (Fig. 3b) and endured strong headwinds mostly at the final stages of the desertcrossing (Fig. 2a) as they overcompensated for sidewinds towards their pre-breeding sites (Fig. 3b).
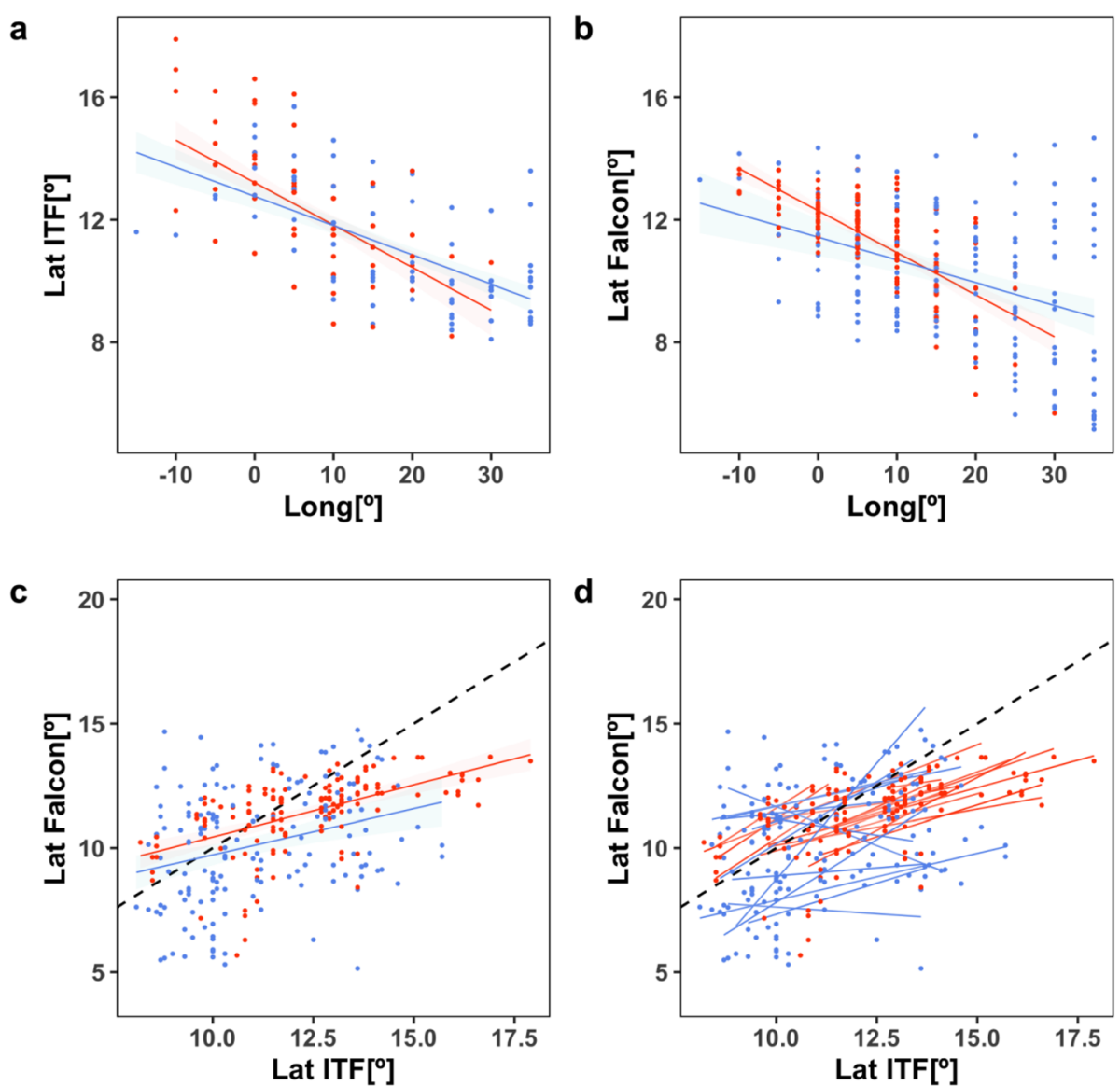

Fig. 4 Seasonal linear relationships between the latitude of trans-Sahelian movements, longitude and the ITF position (autumn = red; spring = blue). $\mathbf{a}, \mathbf{b}$ Latitude of the ITF and the trans-Sahelian migrations of falcons in relation to longitude. $\mathbf{c}$ Latitude of the trans-Sahelian migrations in relation to the latitude of the ITF at corresponding longitudes and times. The black dotted line indicates where latitude of falcons and ITF would match. Points below the black line correspond to cases where a falcon travelled south of the ITF. $\mathbf{d}$ Individual trend lines for each season showing consistency of the linear correlation between falcon and ITF positions 
Table 1 Selecting the best GLMM for the latitude of trans-Sahelian migration

\begin{tabular}{|c|c|c|c|c|c|c|c|}
\hline Model (fixed effects) & df & AIC & $\triangle \mathrm{AIC}$ & AIC Weight & R2 full & R2 fixed & $\mathrm{R} 2$ random \\
\hline$\sim$ long*|TF*season & 10 & 1086 & 0 & 1 & 0.52 & 0.32 & 0.20 \\
\hline$\sim$ long*season & 6 & 1096 & 11 & 0 & 0.48 & 0.32 & 0.17 \\
\hline$\sim$ ITF + long & 5 & 1106 & 21 & 0 & 0.47 & 0.31 & 0.16 \\
\hline$\sim$ long*ITF & 6 & 1108 & 22 & 0 & 0.47 & 0.31 & 0.16 \\
\hline$\sim$ long & 4 & 1116 & 31 & 0 & 0.44 & 0.30 & 0.14 \\
\hline$\sim$ long+season & 5 & 1117 & 31 & 0 & 0.44 & 0.31 & 0.14 \\
\hline$\sim$ ITF*season & 6 & 1139 & 54 & 0 & 0.42 & 0.21 & 0.21 \\
\hline$\sim$ ITF + season & 5 & 1141 & 56 & 0 & 0.41 & 0.22 & 0.19 \\
\hline$\sim \mathrm{ITF}$ & 4 & 1156 & 70 & 0 & 0.37 & 0.18 & 0.19 \\
\hline$\sim$ season & 4 & 1214 & 129 & 0 & 0.23 & 0.09 & 0.13 \\
\hline$\sim$ & 3 & 1245 & 160 & 0 & 0.14 & 0.00 & 0.14 \\
\hline
\end{tabular}

Models included fixed effects for the latitudinal position of the ITF, longitude, season, their additive effects and interaction effects. We also allowed for intercepts to vary randomly between individuals in all models. Models are ranked according to increasing $\triangle \mathrm{AIC} /$ decreasing AIC weight, with the best performing model on top

\section{Route choice along the ITF}

In general, the latitudinal position of both the ITF and the falcons decreased significantly with longitude in both seasons (Fig. 4a-b), although the migration corridor overlapped with the ITF much more closely in spring (Fig. 2). The latitude at which falcons travelled across the Sudan-Sahel zone was significantly and positively correlated with the latitudinal position of the ITF across the full dataset (Fig. 4c), but the effect was more consistent among individuals in autumn than in spring (Fig. 4d). GLMMs showed that ITF could not fully account for the longitudinal decrease in the falcons' latitudinal position, but the ITF position competes with season as a significant predictor variable (Tables 1 and 2). Random individual differences accounted for a similar amount of variation in the latitude of trans-Sahelian migrations as ITF position (Table 2).

\section{Wind and biome effects on migratory performance}

Within seasons, daily travel distances peaked and waned across different geographical regions (Figs. S5-S6), which was largely due to differences in daily travel time

Table 2 Model coefficients as estimated by the best GLMM for the latitude of trans-Sahelian migration

\begin{tabular}{llllll}
\hline Model term & Estimate & Std. Error & $\mathbf{d f}$ & $\mathbf{t}$ value & $\operatorname{Pr}(>|\mathbf{t}|)$ \\
\hline (Intercept) & $\mathbf{9 . 5 3 0}$ & $\mathbf{1 . 1 7 3}$ & $\mathbf{2 9 2 . 8 9 5}$ & $\mathbf{8 . 1 2 4}$ & $<\mathbf{0 . 0 0 1}$ \\
lat_ITF & $\mathbf{0 . 2 2 8}$ & $\mathbf{0 . 0 8 7}$ & $\mathbf{2 9 0 . 0 4 2}$ & $\mathbf{2 . 6 3 7}$ & $\mathbf{0 . 0 0 9}$ \\
long & $\mathbf{- 0 . 3 4 5}$ & $\mathbf{0 . 0 9 3}$ & $\mathbf{2 8 2 . 8 5 6}$ & $\mathbf{- 3 . 6 9 2}$ & $<\mathbf{0 . 0 0 1}$ \\
spring & 1.679 & 2.028 & 282.828 & 0.828 & 0.409 \\
lat_ITF:long & $\mathbf{0 . 0 1 8}$ & $\mathbf{0 . 0 0 8}$ & $\mathbf{2 8 4 . 5 4 0}$ & $\mathbf{2 . 3 8 9}$ & $\mathbf{0 . 0 1 8}$ \\
lat_ITF:spring & -0.232 & 0.159 & 283.446 & -1.463 & 0.145 \\
long:Spring & 0.217 & 0.119 & 281.549 & 1.828 & 0.069 \\
lat_ITF:Iong:Spring & -0.012 & 0.010 & 282.362 & -1.257 & 0.210 \\
\hline
\end{tabular}

We consider coefficient estimates to be significant at $P<0.05$ (bold) budgets between biomes (Fig. S2). We found particularly long travel days over the desert in both seasons, over the sea in spring, and to a lesser extent over the tropical rainforest in autumn (S5-S6). Exploratory analyses further revealed differences in daily mean speed between biomes, with particularly fast travel over the sea in both seasons, and to a lesser extent over the desert (Fig. S6). However, realized tailwinds were higher over the desert than over the sea in autumn, and falcons generally enjoyed weaker tailwinds over the desert than over other biomes in spring (Fig. S6).

Plotting linear relationships showed a highly positive correlation of daily distance with travel time, and of daily mean travel speeds with travel time, in both seasons (Fig. 5a-b). Both daily distance and daily mean travel speeds increased more strongly with travel time in spring than in autumn (Fig. 5a-b: note greater estimates for slopes in spring) and daily mean speeds were greater in spring (Fig. 5b: note greater intercept estimate in spring).

Daily travel time itself was best explained by biome differences and not driven by realized tailwind (Table S5, but note very low $\mathrm{R}^{2}$ of biome model). By contrast, daily distance and daily mean travel speed were both positively correlated with daily realized tailwind (Fig. 5iii, v; Table S5). Our best models included additive effects of realized tailwind and biome on daily distance, and interaction effects of realized tailwind, biome and season on daily mean travel speed (Table S5). Analogous models using tailwinds along the GCR instead of realized tailwinds as a predictor showed a similarly positive wind effect on daily distance and daily mean travel speed during autumn, but not so during spring migration (Fig. 5iv, vi; Table S6). Random individual differences did not account for substantial variation in any of the response variables. 


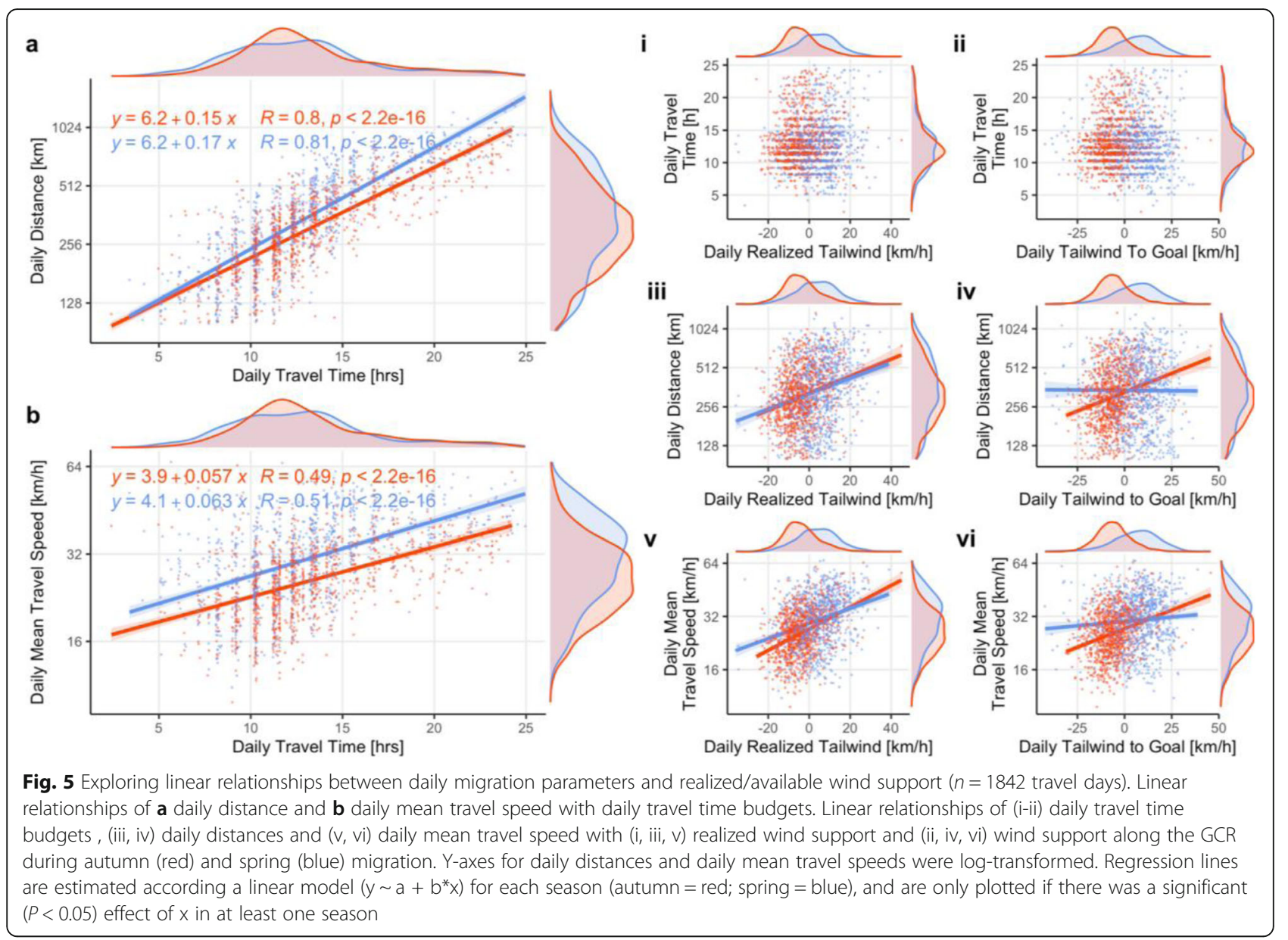

Our final model selection procedure revealed that daily distance (Table 3) and daily mean travel speeds (Table S7) were best explained by models including interaction effects of daily travel time and biome with realized tailwind and absolute realized sidewind strength. These models accounted for $>71 \%$ of variation in daily distance (Table 3 ), $>45 \%$ in daily mean travel speed (Table S7), with no remaining seasonal differences in these performance metrics. Detailed outputs for these models (Table 4) revealed significant positive effects of realized tailwind and daily travel time, and a negative effect of the biome 'other' and a positive effect of 'sea' (with 'desert' being the reference group for estimating the intercept), and biome-specific effects of travel time on both distance and speed. In addition, we found biome-specific effects of realized tailwinds on daily mean travel speeds, and no evidence for random individual or year differences in daily distance nor travel speed.

\section{Discussion}

The latitudinal shift of the ITF and its associated wind fields is one of the most defining features of the Africa's climate. Here, we show that wind support experienced by a trans-African migrant falcon plays a key role in shaping their daily, regional and seasonal performance, in addition to wind-independent adjustments in daily travel time. Falcons thereby tend to improve wind support by drifting through strong adverse wind fields, while compensating for displacements through relatively weak wind fields. They tolerated losses in wind support by detouring from the GCR in areas with weak or highly supportive prevailing winds. In contrast to Mediterranean colonies, spring migrations to the Canarian breeding grounds were much longer in length and substantially longer in overall duration than the autumn migration [27, 30]. However, as in other migrant birds where slower spring than autumn migrations have been reported, the added migration time was mainly due to the birds making a greater number of stop-overs during spring migration [53-55]. Greater tailwind support in spring meant Canarian falcons could actually cover their longer spring detours in the same number of travel days as the shorter autumn route. That said, the greater realized wind support in spring was due to the prevailing winds over Africa being generally more supportive for westward than eastward migration. In fact, falcons 
Table 3 Selecting the best GLMM for log-transformed daily distance ( $n=1842$ travel days)

\begin{tabular}{|c|c|c|c|c|c|c|c|}
\hline Model (fixed effects) & df & AIC & $\Delta \mathrm{AIC}$ & AIC Weight & R2 full & R2 fixed & $\mathrm{R} 2$ random \\
\hline$\sim$ (tailwind_track + abs (sidewind_track)) $*$ travel_hrs $*$ biome & 27 & 758.48 & 0.00 & 1.00 & 0.71 & 0.70 & 0.00 \\
\hline$\sim($ tailwind_track + abs (sidewind_track)) * biome + season & 12 & 801.46 & 42.98 & 0.00 & 0.20 & 0.19 & 0.01 \\
\hline$\sim$ biome * travel_hrs & 9 & 817.81 & 59.33 & 0.00 & 0.68 & 0.67 & 0.01 \\
\hline$\sim($ tailwind_track + abs (sidewind_track) $) *$ travel_hrs + biome & 15 & 849.94 & 91.46 & 0.00 & 0.70 & 0.69 & 0.00 \\
\hline$\sim$ travel_hrs * abs (sidewind_track) & 10 & 859.93 & 101.45 & 0.00 & 0.65 & 0.63 & 0.01 \\
\hline$\sim$ tailwind_track * travel_hrs & 9 & 878.35 & 119.87 & 0.00 & 0.68 & 0.67 & 0.01 \\
\hline abs (sidewind_track) + travel_hrs & 7 & 879.77 & 121.29 & 0.00 & 0.65 & 0.63 & 0.01 \\
\hline biome + abs (sidewind_track) & 7 & 895.05 & 136.57 & 0.00 & 0.14 & 0.13 & 0.01 \\
\hline season + abs (sidewind_track) & 6 & 908.30 & 149.82 & 0.00 & 0.03 & 0.02 & 0.01 \\
\hline$\sim$ season + biome + travel_hrs & 7 & 909.63 & 151.15 & 0.00 & 0.67 & 0.67 & 0.00 \\
\hline$\sim$ season * tailwind_track & 9 & 930.52 & 172.04 & 0.00 & 0.08 & 0.07 & 0.01 \\
\hline$\sim$ (tailwind_track + abs (sidewind_track)) * season & 11 & 943.53 & 185.05 & 0.00 & 0.09 & 0.08 & 0.01 \\
\hline biome + tailwind_track + abs (sidewind_track) & 8 & 992.51 & 234.03 & 0.00 & 0.18 & 0.18 & 0.01 \\
\hline$\sim$ tailwind_track + abs (sidewind_track) & 7 & 1028.47 & 269.99 & 0.00 & 0.09 & 0.08 & 0.01 \\
\hline$\sim$ season + tailwind_track + biome & 7 & 1045.48 & 287.00 & 0.00 & 0.18 & 0.17 & 0.01 \\
\hline$\sim$ season + tailwind_track & 6 & 1055.16 & 296.68 & 0.00 & 0.08 & 0.07 & 0.01 \\
\hline$\sim$ season + abs (sidewind_track) + travel_hrs & 7 & 1105.61 & 347.12 & 0.00 & 0.66 & 0.65 & 0.00 \\
\hline$\sim$ biome + travel_hrs & 6 & 1110.26 & 351.78 & 0.00 & 0.67 & 0.66 & 0.01 \\
\hline abs (sidewind_track) & 5 & 1125.04 & 366.56 & 0.00 & 0.02 & 0.01 & 0.01 \\
\hline$\sim($ tailwind_track + abs (sidewind_track)) * travel_hrs * season & 24 & 2575.59 & 1817.11 & 0.00 & 0.69 & 0.69 & 0.00 \\
\hline$\sim\left(\right.$ tailwind_track + abs (sidewind_track)) ${ }^{*}$ travel_hrs + season & 15 & 2586.38 & 1827.90 & 0.00 & 0.69 & 0.68 & 0.00 \\
\hline$\sim($ tailwind_track + abs $($ sidewind_track $)) *$ biome ${ }^{*}$ season & 16 & 2587.98 & 1829.50 & 0.00 & 0.21 & 0.20 & 0.01 \\
\hline$\sim$ biome $*$ tailwind_track & 9 & 2611.55 & 1853.07 & 0.00 & 0.18 & 0.17 & 0.01 \\
\hline$\sim$ travel_hrs + tailwind_track + abs (sidewind_track) & 8 & 2619.54 & 1861.06 & 0.00 & 0.68 & 0.68 & 0.01 \\
\hline$\sim($ tailwind_track + abs $($ sidewind_track $)) *$ biome & 11 & 2619.68 & 1861.20 & 0.00 & 0.20 & 0.19 & 0.01 \\
\hline$\sim$ season * travel_hrs & 9 & 2621.50 & 1863.02 & 0.00 & 0.65 & 0.65 & 0.00 \\
\hline$\sim($ tailwind_track + abs (sidewind_track) $) *$ travel_hrs & 11 & 2685.52 & 1927.04 & 0.00 & 0.68 & 0.68 & 0.01 \\
\hline$\sim$ season * abs (sidewind_track) & 9 & 2691.59 & 1933.11 & 0.00 & 0.03 & 0.02 & 0.01 \\
\hline$\sim$ tailwind_track * abs (sidewind_track) & 10 & 2695.00 & 1936.52 & 0.00 & 0.09 & 0.08 & 0.01 \\
\hline$\sim$ biome + tailwind_track + travel_hrs & 8 & 2697.32 & 1938.84 & 0.00 & 0.69 & 0.69 & 0.00 \\
\hline$\sim$ season * biome & 8 & 2704.51 & 1946.03 & 0.00 & 0.15 & 0.14 & 0.01 \\
\hline$\sim$ biome + tailwind_track & 7 & 2707.39 & 1948.91 & 0.00 & 0.18 & 0.17 & 0.01 \\
\hline$\sim$ season + travel_hrs & 6 & 2808.74 & 2050.26 & 0.00 & 0.65 & 0.65 & 0.00 \\
\hline$\sim$ season + biome + abs (sidewind_track) & 7 & 2809.29 & 2050.81 & 0.00 & 0.15 & 0.14 & 0.01 \\
\hline$\sim$ tailwind_track + travel_hrs & 7 & 2810.58 & 2052.10 & 0.00 & 0.68 & 0.67 & 0.01 \\
\hline biome * abs (sidewind_track) & 9 & 2810.77 & 2052.29 & 0.00 & 0.15 & 0.15 & 0.01 \\
\hline$\sim$ biome & 5 & 2832.09 & 2073.61 & 0.00 & 0.14 & 0.13 & 0.01 \\
\hline$\sim$ travel_hrs & 6 & 2834.03 & 2075.55 & 0.00 & 0.64 & 0.63 & 0.01 \\
\hline$\sim$ season + tailwind_track + travel_hrs & 7 & 2835.69 & 2077.21 & 0.00 & 0.68 & 0.68 & 0.00 \\
\hline$\sim$ season + tailwind_track + abs (sidewind_track) & 7 & 2928.90 & 2170.42 & 0.00 & 0.09 & 0.08 & 0.01 \\
\hline$\sim$ season + biome & 6 & 2932.39 & 2173.91 & 0.00 & 0.14 & 0.14 & 0.01 \\
\hline$\sim$ tailwind_track & 5 & 2950.18 & 2191.70 & 0.00 & 0.08 & 0.07 & 0.01 \\
\hline season & 5 & 2951.18 & 2192.70 & 0.00 & 0.02 & 0.01 & 0.01 \\
\hline$\sim(1 \mid$ dev $)+(1 \mid y r)$ & 4 & 2963.73 & 2205.25 & 0.00 & 0.01 & 0.00 & 0.01 \\
\hline
\end{tabular}


We tested an exhaustive set of models including fixed effects of tailwind and sidewind along the realized travel direction, daily travel time, season, their additive effects, and interaction effects between wind variables and daily travel time, biome and season. We further allowed intercepts to vary randomly between individuals and between years. Models are ranked according to increasing $\triangle \mathrm{AIC}$ values, with the best performing model on top

compromised wind support during spring detours over hospitable landscapes, whereas in autumn they avoided strong headwinds by detouring. Furthermore, we only found evidence of individual variation in performance parameters in spring (i.e. stop-over days), and falcons also showed more individual variation in route choice in this season. This suggests a stronger environmental canalization of route choice/development in opposing autumn wind regimes, whereas supportive spring wind fields allow for diversification of individual migration routines.

As in other fly-forage migrants, including several falcon species, we found that flexible travel time budgets are the main determinant of daily travel distances [56, 57]. We further show that daily travel time budgets were largely independent of wind support [58], and mainly varied due to falcons extending travel time over barriers (incl. nocturnal travel) and reducing travel time over hospitable habitats [28, 31]. Indeed, Eleonora's falcons sometimes had to confront adverse winds while making 'fast' non-stop flights across ecological barriers (e.g. across the Mozambique Channel) and other times travelled few hours per day in supportive winds over hospitable landscapes (e.g. East Africa in spring). Despite regional variations in travel time budgets, realized tailwinds had a strong positive effect on daily mean travel speeds in both seasons, and models accounting for the combined effect of travel time and tailwind accounted for more than $60 \%$ of variation in daily travel distances, whereby the seasonal difference in realized wind support explains the marked seasonal difference in travel performance. Therefore, the faster spring travel is not evidence of a time-minimizing strategy, but rather a result of favourable seasonal conditions [59], whereby the late breeding and long pre-breeding period of Eleonora's falcons likely buffers selection for time-minimization and early arrival to the summer range [36, 39].

As expected, the crossing of the ITF marked the end of the 'desert'-crossing, and like individuals from other colonies, Canarian Eleonora's falcons tended to make short stop-overs in recently rainfed areas in the Sahel $[28,30]$. However, falcons from the Canary Islands displayed an even more pronounced zig-zag migration pattern than those from the westernmost Mediterranean colonies by migrating eastward for hundreds - thousands of km's before reorienting southeast to Madagascar (Fig. S8). The latitude at which these longitudinal movements occurred was correlated with the ITF's position (which varies depending on date, longitude and year), and we argue that flying near the ITF allows falcons to compensate for the drift over the desert in weaker winds than they could by travelling over more vegetated areas further south, where we might expect higher food availability (i.e. insects). However, it is also possible that the monsoon rain front south of the ITF is characterized by the presence of particularly profitable prey such as desert locusts [24]. By detouring far east across the Sahel falcons also seemed to reduce the distance flown over the equatorial rainforest by $500-1000 \mathrm{~km}$ compared to the GCR. Combined with a regional peak in nocturnal flight activity, this suggests that falcons perceive the tropical rainforest belt as a considerable barrier [28, 60]. Besides food availability, the humid tropical forests may constitute a migration barrier due to climatic conditions that hinder soaring (e.g. limited thermal convection) as well as flapping flight (e.g. precipitation). Falcons again reduced daily travel times and made irregular short stop-overs when reaching the East African savannahs. Importantly, they reduced headwind resistance through strong adverse wind fields here, showing how wind regimes themselves can form migration barriers even over hospitable landscapes [10].

In spring, the protracted trans-oceanic flight from northern Madagascar to East Africa was not associated with gains in wind support because this route happened to be closely aligned with the GCR to the Canary Islands. This behaviour should nevertheless be considered as an adaptive drift response because falcons from eastern colonies -for whom this route does represent a detour- also use this route to exploit strong prevailing winds [29, 31] (Fig. S8). Moreover, the highly mixed pattern of overdrift and overcompensation behaviour during spring migration indicates that falcons intended to reach some intermediate goals instead of leveraging wind support along the GCR directly. The majority of the Canarian falcons detoured into the Horn of Africa after reaching mainland Africa, like conspecifics from Mediterranean colonies (Fig. S8), confirming that this is a key stop-over region for the species as a whole, as it is for several other insectivorous Afro-Palearctic migrants in spring $[61,62]$. Falcons are assumed to prey on large or superabundant insects following early spring rains in this region (so-called Belg rains [27, 63]). However, there is insufficient field data to determine what foraging opportunities explain the importance of this stop-over in the extant migratory network of our fringe study population. It has been suggested the stop-over is a genetically conserved strategy [27]. But while intense Belg rains have been a stable climatic feature in the Horn of Africa for millennia they have been steadily declining over the last century as a result of global warming [64]. 
Table 4 Fixed effects on log-transformed daily distance and daily mean travel speed as estimated by our best GLMMs

\begin{tabular}{|c|c|c|c|c|c|}
\hline Response variable & Model term & Estimate & Std. Error & $z$ value & $\operatorname{Pr}(>|z|)$ \\
\hline \multirow[t]{24}{*}{ Log (Daily Distance) } & (Intercept) & 4.628 & 0.121 & 38.228 & 0.000 \\
\hline & tailwind_track & 0.064 & 0.027 & 2.349 & 0.019 \\
\hline & abs (sidewind_track) & 0.023 & 0.032 & 0.733 & 0.463 \\
\hline & travel_hrs & 0.099 & 0.008 & 12.406 & 0.000 \\
\hline & biome_humid forest & -0.165 & 0.274 & -0.602 & 0.547 \\
\hline & biome_other & -0.509 & 0.131 & -3.875 & 0.000 \\
\hline & biome_sea & 0.481 & 0.180 & 2.678 & 0.007 \\
\hline & tailwind_track: travel_hrs & -0.002 & 0.002 & -0.830 & 0.407 \\
\hline & abs (sidewind_track): travel_hrs & -0.001 & 0.002 & -0.554 & 0.580 \\
\hline & tailwind_track: biome_humid forest & -0.167 & 0.108 & -1.543 & 0.123 \\
\hline & tailwind_track: biome_other & -0.037 & 0.029 & -1.260 & 0.208 \\
\hline & tailwind_track: biome_sea & -0.053 & 0.035 & -1.498 & 0.134 \\
\hline & abs (sidewind_track): biome_humid forest & -0.017 & 0.089 & -0.186 & 0.852 \\
\hline & abs (sidewind_track): biome_other & 0.030 & 0.036 & 0.829 & 0.407 \\
\hline & abs (sidewind_track): biome_sea & -0.065 & 0.049 & -1.325 & 0.185 \\
\hline & travel_hrs: biome_humid forest & 0.003 & 0.019 & 0.148 & 0.882 \\
\hline & travel_hrs: biome_other & 0.024 & 0.009 & 2.637 & 0.008 \\
\hline & travel_hrs: biome_sea & -0.029 & 0.012 & -2.439 & 0.015 \\
\hline & tailwind_track: travel_hrs: biome_humid forest & 0.008 & 0.007 & 1.053 & 0.293 \\
\hline & tailwind_track: travel_hrs: biome_other & 0.002 & 0.002 & 1.217 & 0.224 \\
\hline & tailwind_track: travel_hrs: biome_sea & 0.002 & 0.002 & 0.958 & 0.338 \\
\hline & abs (sidewind_track): travel_hrs: biome_humid forest & 0.001 & 0.006 & 0.084 & 0.933 \\
\hline & abs (sidewind_track): travel_hrs: biome_other & -0.002 & 0.003 & -0.641 & 0.521 \\
\hline & abs (sidewind_track): travel_hrs: biome_sea & 0.005 & 0.004 & 1.319 & 0.187 \\
\hline \multirow[t]{20}{*}{ Log (Daily Mean Travel Speed) } & (Intercept) & 1.820 & 0.101 & 18.014 & 0.000 \\
\hline & tailwind_track & 0.068 & 0.023 & 3.021 & 0.003 \\
\hline & abs (sidewind_track) & -0.011 & 0.026 & -0.402 & 0.688 \\
\hline & travel_hrs & 0.029 & 0.007 & 4.312 & 0.000 \\
\hline & biome_humid forest & -0.159 & 0.228 & -0.696 & 0.487 \\
\hline & biome_other & -0.440 & 0.109 & -4.020 & 0.000 \\
\hline & biome_sea & 0.428 & 0.150 & 2.863 & 0.004 \\
\hline & tailwind_track: travel_hrs & -0.002 & 0.002 & -1.328 & 0.184 \\
\hline & abs (sidewind_track): travel_hrs & 0.000 & 0.002 & 0.263 & 0.792 \\
\hline & tailwind_track: biome_humid forest & -0.158 & 0.090 & -1.748 & 0.081 \\
\hline & tailwind_track: biome_other & -0.029 & 0.024 & -1.204 & 0.229 \\
\hline & tailwind_track: biome_sea & -0.051 & 0.029 & -1.759 & 0.079 \\
\hline & abs (sidewind_track): biome_humid forest & -0.014 & 0.074 & -0.183 & 0.855 \\
\hline & abs (sidewind_track): biome_other & 0.045 & 0.030 & 1.512 & 0.131 \\
\hline & abs (sidewind_track): biome_sea & 0.023 & 0.041 & 0.562 & 0.574 \\
\hline & travel_hrs: biome_humid forest & 0.003 & 0.016 & 0.169 & 0.866 \\
\hline & travel_hrs: biome_other & 0.020 & 0.007 & 2.623 & 0.009 \\
\hline & travel_hrs: biome_sea & -0.024 & 0.010 & -2.436 & 0.015 \\
\hline & tailwind_track: travel_hrs: biome_humid forest & 0.008 & 0.006 & 1.359 & 0.174 \\
\hline & tailwind_track: travel_hrs: biome_other & 0.002 & 0.002 & 1.281 & 0.200 \\
\hline
\end{tabular}


Table 4 Fixed effects on log-transformed daily distance and daily mean travel speed as estimated by our best GLMMs (Continued)

\begin{tabular}{|c|c|c|c|c|c|}
\hline Response variable & Model term & Estimate & Std. Error & $z$ value & $\operatorname{Pr}(>|z|)$ \\
\hline & tailwind_track: travel_hrs: biome_sea & 0.002 & 0.002 & 1.275 & 0.202 \\
\hline & abs (sidewind_track): travel_hrs: biome_humid forest & 0.000 & 0.005 & 0.087 & 0.930 \\
\hline & abs (sidewind_track): travel_hrs: biome_other & -0.003 & 0.002 & -1.313 & 0.189 \\
\hline & abs (sidewind_track): travel_hrs: biome_sea & -0.001 & 0.003 & -0.312 & 0.755 \\
\hline
\end{tabular}

We consider coefficient estimates to be significant at $P<0.05$ (bold)

Moreover, spring rains are subject to great interannual and sub-seasonal variability under current climatic conditions $[65,66]$ and droughts in the Horn of Africa have been linked to delayed spring migration and even failed reproduction of migrant birds [62]. In our study two-three falcons consistently forewent the Ethiopian stop-overs, stopping-over in rainfed areas in Uganda and South Sudan instead (Fig. S7). This indicates at least some flexibility in the development of spring routes, even in areas that seem to be of great significance for the species as a whole.

Frequent nocturnal travel over the eastern Sahel in spring suggests that the decision to travel eastward along the ITF is not motivated by local foraging opportunities, and rather by barrier avoidance. Taken together with previous tracking studies from Mediterranean colonies we suggest the existence of a migratory divide in spring desert-crossing corridors between western and eastern colonies (Fig. S8). The latter (e.g. Greek and Cypriotic falcons) tend to travel directly northward across the eastern Sahara or along the eastern Red Sea coast and reorient to the breeding colony after reaching the eastern Mediterranean region. By contrast, falcons from the Canary Islands and western Mediterranean colonies tend to first travel westward over the Sahel, thus postponing the desert-crossing to the west of $15 \mathrm{E}$ (Fig. S8). For Canarian Eleonora's falcons, postponing the desert-crossing until Central or West Africa lengthens the spring migration by $>500 \mathrm{~km}$ but reduces the desert-crossing distance by $>1500 \mathrm{~km}$ as opposed to returning from Ethiopia along the GCR. Circumventing the Sahara along the eastern side would extend the spring migration by $>1000 \mathrm{~km}$, with no obvious gains in wind support or foraging opportunities.

Even though previous studies reported low individual repeatability of seasonal route choice in Eleonora's falcons, a common pattern in Africa-Eurasian migrants, we found evidence for substantial individual differences in spring stop-overs and the latitude at which falcons migrated across the Sahel-Sudan zone during spring migration, in contrast to falcons converging in a relatively narrow latitudinal corridor south of the ITF in autumn. In fact, trans-Sahelian routes were much more individually variable in spring, with individuals at one end of the spectrum overshooting the ITF over the eastern Sahel and initiating desert-crossings from Central Africa, while others wandered extensively in West Africa before crossing the desert. Individually repeatable spring stop-over sites, particularly in East Africa, seem to act as anchoring points for individual routes across years (Fig. S7). This finding, combined with the later, slower migration of juveniles along markedly different routes than adults [27, 30], suggests that route development is mediated by exploration-refinement learning [67-70]. Additional tracking studies involving juvenile birds would be needed to determine how orientation behaviour and migratory performance are refined through individual experience, and how they respond to intra-generational changes in environmental conditions.

\section{Conclusions}

By contextualizing route choice and migratory performance patterns in prevailing winds and seasonal climates across distinct biomes we revealed a complex interplay of adaptive drift and barrier-avoidance responses in the trans-equatorial migration of a fly-forage migrant. Eleonora's falcons engaged in adaptive drift to maximize wind support over 'hard' barriers (i.e. desert and sea) but, importantly, also through adverse wind fields over hospitable landscapes. By contrast, in weak or favourable wind fields falcons often leveraged wind support by detouring from the GCR, for example to exploit habitual spring stop-overs in the Horn of Africa and to circumvent the 'soft' barrier of the Congo Basin in autumn. Daily travel distances vary greatly depending on daily travel time budgets, with particularly long flights occurring over barriers. However, the favourable orientation of spring wind regimes for westward migration is what permitted falcons to travel faster when heading to their breeding grounds, rather than time-minimizing behaviours per se.

Longitudinal movements along the ITF were associated with reduced wind support in both seasons and were more individually variable in spring. Even though this study offers an extreme example of longitudinal migration, variation in trans-Saharan migration patterns among and within other species can likely be explained in part from common responses to the seasonally shifting position of the ITF and its associated atmospheric circulation patterns. For example, birds that cross the 
Sahara in August-September can be expected to escape the influence of strong desert winds and to encounter more hospitable conditions and calmer winds hundreds of km's further north than those that cross in OctoberNovember. The ITF may thus offer a temporally dynamic coordinate system within which to compare migration patterns across populations and species.

\section{Supplementary Information}

The online version contains supplementary material available at https://doi. org/10.1186/s40462-021-00272-8.

Additional file 1 : Fig. S1. (a) Flyway patterns in nocturnal flight activity and (b) daily flight activity-budgets of Eleonora's falcons. Fig. S2 (a) Biome-annotation of autumn and spring migration routes and (b) daily flight activity-budgets of Eleonora's falcons across each biome in each season. Fig. $\mathbf{S 3}$ Linear relationships of mean individual (a) trip duration, (b) stop-over days, (c) travel days, and (d) daily tailwind assistance with mean individual detour extent in autumn (red, $n=19)$ and spring (blue, $n=18)$. Fig. $\mathbf{S 4}$ Regional differences in orientation behaviour in response to sidewinds towards the seasonal destination. Fig. S5 Regional variation in (a) daily travel time, (b) daily beeline distances and (c) daily mean travel speeds during autumn (left) and spring (right) migration. Fig. S6 Biome differences in performance and wind support metrics during autumn (left) and spring (right) migration. Fig. S7 Individual differences in route choice. Fig. $\mathbf{S 8}$ Approximate seasonal migration routes by adult Eleonora's falcons from and to colonies across the breeding range.

Additional file 2 : Table S1. Seasonal summary statistics for 19 falcons tracked over a total of 75 migrations. Table S2. Summary statistics for seasonal performance per sex. Table S3. Selecting best GLMMs for tripscale movement statistics $(n=75)$ as a function of detour extent and season. Table S4. Fixed effects of detour extent and season trip-scale movement statistics according to most parsimonious GLMMs (Table S2). Table S5. Selecting best GLMMs for daily movement statistics ( $n=1842$ travel days) as a function of tailwind along the track, biome and season. Table S6. Selecting best GLMMs for daily movement statistics ( $n=1842$ travel days) as a function of tailwind relative to the goal, biome and season.

Table S7. Selecting the best GLMM for log-transformed daily mean travel speed ( $n=1842$ travel days)

Additional file 3. Codes for reproducing seasonal NDVI maps in Google Earth Engine.

\section{Acknowledgements}

We thank J.J. Moreno, M. de la Riva, J.L. Barroso, M. Majem and M. Moreno for assistance with the fieldwork. We also thank the Jordan and López Arias families, owners of Alegranza and Montaña Clara islets, respectively, for providing work permits. UVA-BiTS studies are facilitated by infrastructures for e-Ecology, developed with the support of LifeWatch, and conducted on the Dutch national e-infrastructure with the support of SURF Cooperative. We thank Camilo Carneiro and one anonymous reviewer for their constructive feedback on this manuscript.

\section{Authors' contributions}

WMGV, LG, JF conceived the study with significant input from WB and DSV. LG coordinated the Eleonora's falcon project with significant help of JF and WB. WB advised on programming of GPS-loggers and data collection. LG, DV and WMGV conducted field work. WMGV wrote the paper and conducted the analyses with guidance from all co-authors. The author(s) read and approved the final manuscript.

\section{Funding}

The study was partly funded by the Cabildo de Lanzarote, European Social Fund, and adaptation and improvement of the internationalization of einfrastructure of the ICTS-RBD for the ESFRI-LifeWatch. Project coordinator LG was supported by the Marie Skłodowska-Curie Actions of the EU Commission (project 'EcoEvoClim', grant number 747729). WMGV lead the research as part of a Juan de la Cierva Formación fellowship (FJCl-2017-34396).

\section{Availability of data and materials}

Tracking data are stored in the UvA-BiTS database and available upon request. Annotated $\mathrm{R}$ code to reproduce the analyses is available via WMGV's Github (https://github.com/Wouter-Vansteelant/Vansteelant-etal-2021Movement-Ecology) and automatically installs all required packages. ITF positional data were downloaded from NOAA-CPC via http://www.cpc.ncep. noaa.gov/products/fews/ITCZ/itcz.shtml. All other weather data are freely available through NOAA and are automatically downloaded and processed by the $\mathrm{R}$ code we provided. Code to reproduce seasonal NDVI maps in Google Earth Engine is provided in Additional file 3.

\section{Declarations}

\section{Ethics approval}

Falcon trapping and tagging were approved by the Dirección General de Protección de la Naturaleza (Viceconsejería de Medio Ambiente), Canarian Government (permits n² 2014/2224, 2015/3835, 2017/6829, 2020/10521).

\section{Competing interests}

The authors declare that they have no competing interests.

\section{Author details}

${ }^{1}$ Estación Biológica de Doñana, CSIC. Cartuja TA-10, Edificio I, Calle Américo Vespucio, s/n, 41092 Sevilla, Spain. ${ }^{2}$ Institute for Biodiversity and Ecosystem Dynamics (IBED), University of Amsterdam, Sciencepark 904, 1098 XH Amsterdam, The Netherlands. ${ }^{3}$ Department of Biodiversity, Ecology and Evolution. Faculty of Biology, Complutense University of Madrid, C/ José Antonio Novais 2, 28040 Madrid, Spain. ${ }^{4}$ German Center for Integrative Biodiversity Research (iDiv), Deutscher Platz 5e, Halle-Jena-Leipzig, Leipzig, Germany.

Received: 22 February 2021 Accepted: 10 June 2021

Published online: 13 July 2021

\section{References}

1. Vardanis $Y$, Klaassen RHG, Strandberg R, Alerstam T. Individuality in bird migration: routes and timing. Biol Lett. 2011;7(4):502-5. https://doi.org/10.1 098/rsbl.2010.1180.

2. Vardanis $Y$, Nilsson JÅ, Klaassen RHG, Strandberg R, Alerstam T. Consistency in long-distance bird migration: contrasting patterns in time and space for two raptors. Anim Behav. 2016;113:177-87. https://doi.org/10.1016/j.anbeha v.2015.12.014

3. Cresswell W. Migratory connectivity of Palaearctic-African migratory birds and their responses to environmental change: the serial residency hypothesis. Ibis (Lond. 1859). 2014;156:493-510.

4. Stull RB. An introduction to boundary-layer meteorology. Dordrecht: Reidel Publishing Co.; 1988. https://doi.org/10.1007/978-94-009-3027-8.

5. Liechti F. Birds: blowin' by the wind? J Ornithol. 2006;147:202-11.

6. Alerstam T. Detours in bird migration. J Theor Biol. 2001;209(3):319-31. https://doi.org/10.1006/jtbi.2001.2266

7. Alerstam T. Optimal use of wind by migrating birds: combined drift and overcompensation. J Theor Biol. 1979;79(3):341-53. https://doi.org/10.1016/ 0022-5193(79)90351-5.

8. Kranstauber B, Weinzierl R, Wikelski M, Safi K. Global aerial flyways allow efficient travelling. Ecol Lett. 2015;18(12):1338-45. https://doi.org/10.1111/ ele.12528.

9. Wainwright CE, Stepanian PM, Horton KG. The role of the US Great Plains low-level jet in nocturnal migrant behavior. Int J Biometeorol. 2016;60(10): 1531-42. https://doi.org/10.1007/s00484-016-1144-9.

10. Shamoun-Baranes J, Liechti F, Vansteelant WMG. Atmospheric conditions create freeways, detours and tailbacks for migrating birds. J Comp Physiol A Neuroethol Sens, Neural, Behav Physiol. 2017;203(6-7):509-29. https://doi. org/10.1007/s00359-017-1181-9.

11. Shaffer SA, Tremblay Y, Weimerskirch H, Scott D, Thompson DR, Sagar PM, et al. Migratory shearwaters integrate oceanic resources across the Pacific Ocean in an endless summer. Proc Natl Acad Sci U S A. 2006;103(34):12799_ 802. https://doi.org/10.1073/pnas.0603715103.

12. González-Solís J, Felicísimo A, Fox JW, Afanasyev V, Kolbeinsson Y, Muñoz J. Influence of sea surface winds on shearwater migration detours. Mar Ecol Prog Ser. 2009;391:221-30. https://doi.org/10.3354/meps08128. 
13. Hromádková T, Pavel V, Flousek J, Briedis M. Seasonally specific responses to wind patterns and ocean productivity facilitate the longest animal migration on earth. Mar Ecol Prog Ser. 2020;638:1-12. https://doi.org/10.33 54/meps13274.

14. Klaassen RHG, Hake M, Strandberg R, Alerstam T. Geographical and temporal flexibility in the response to crosswinds by migrating raptors. Proc R Soc B-Biol Sci. 2011;278(1710):1339-46. https://doi.org/10.1098/rspb.201 0.2106 .

15. Vansteelant WMG, Shamoun-Baranes J, van Diermen J, van Manen W, Bouten W. Seasonal detours by soaring migrants shaped by wind regimes along the East Atlantic flyway. J Anim Ecol. 2017;86(2):179-91. https://doi. org/10.1111/1365-2656.12593

16. Norevik G, Åkesson S, Artois T, Beenaerts N, Conway G, Cresswell B, et al. Wind-associated detours promote seasonal migratory connectivity in a flapping flying long-distance avian migrant. J Anim Ecol. 2020;89(2):635-46. https://doi.org/10.1111/1365-2656.13112.

17. Fan S, Zhao Q, Li H, Zhu B, Dong S, Xie Y, et al. Cyclical helping hands: seasonal tailwinds differentially affect migrating oriental storks (Ciconia boyciana) travel speed. Avian Res. 2020;11(1):10. https://doi.org/10.1186/s4 0657-020-00196-8.

18. Gill RE, Douglas DC, Handel CM, Tibbitts TL, Hufford G, Piersma T. Hemispheric-scale wind selection facilitates bar-tailed godwit circummigration of the Pacific. Anim Behav. 2014;90:117-30. https://doi.org/10.101 6/j.anbehav.2014.01.020.

19. Bulte M, McLaren JD, Bairlein F, Bouten W, Schmaljohann H, ShamounBaranes J. Can wheatears weather the Atlantic? Modeling nonstop transAtlantic flights of a small migratory songbird. Auk. 2014;131(3):363-70. https://doi.org/10.1642/AUK-13-233.1.

20. Nourani E, Yamaguchi NM, Manda A, Higuchi H. Wind conditions facilitate the seasonal water-crossing behaviour of Oriental Honey-buzzards Pernis ptilorhynchus over the East China Sea. Ibis (Lond 1859). 2016;158:506-18.

21. Green M, Alerstam T, Gudmundsson GA, Hedenström A, Piersma T. Do Arctic waders use adaptive wind drift? J Avian Biol. 2004;35(4):305-15. https://doi.org/10.1111/j.0908-8857.2004.03181.x.

22. Nicholson SE. The ITCZ and the seasonal cycle over equatorial Africa. Bull Am Meteorol Soc. 2018;99(2):337-48. https://doi.org/10.1175/BAMS-D-16-02 87.1.

23. Nicholson SE. The west African Sahel: a review of recent studies on the rainfall regime and its interannual variability. ISRN Meteorol. 2013;453521. https://doi.org/10.1155/2013/453521.

24. Lélé MI, Lamb PJ. Variability of the intertropical front (ITF) and rainfall over the west African Sudan-Sahel zone. J Clim. 2010;23(14):3984-4004. https:// doi.org/10.1175/2010JCLI3277.1.

25. Moreau RE. The Palearctic-African bird migration systems. London: Academic Press; 1972.

26. Elkins N. Weather and bird behaviour. London: T \& AD Poyser Ltd; 2010.

27. Gschweng M, Kalko EKV, Querner U, Fiedler W, Berthold P. All across Africa: highly individual migration routes of Eleonora's falcon. Proc R Soc B-Biological Sci. 2008:275(1653):2887-96. https://doi.org/10.1098/rspb.2008.0575.

28. López-López P, Limiñana R, Mellone U, Urios V. From the Mediterranean Sea to Madagascar: Are there ecological barriers for the long-distance migrant Eleonora's falcon? Landsc Ecol. 2010;25:803-13.

29. Kassara C, Fric J, Gschweng M, Sfenthourakis S. Complementing the puzzle of Eleonora's falcon (Falco eleonorae) migration: new evidence from an eastern colony in the Aegean Sea. J Ornithol. 2012;153(3):839-48. https:// doi.org/10.1007/s10336-011-0802-2.

30. Mellone U, López-López P, Limiñana R, Piasevoli G, Urios V. The transequatorial loop migration system of Eleonora's falcon: differences in migration patterns between age classes, regions and seasons. J Avian Biol. 2013;44:417-26.

31. Hadjikyriakou TG, Nwankwo EC, Virani MZ, Kirschel ANG. Habitat availability influences migration speed, refueling patterns and seasonal flyways of a flyand-forage migrant. Mov Ecol. 2020;8(1):10. https://doi.org/10.1186/s40462020-0190-4

32. Mellone U, López-López P, Limiñana R, Urios V. Weather conditions promote route flexibility during open ocean crossing in a long-distance migratory raptor. Int J Biometeorol. 2011;55(4):463-8. https://doi.org/10.1 007/s00484-010-0368-3.

33. Mellone U, Limiñana R, López-López P, Urios V. Regional and agedependent differences in the effect of wind on the migratory routes of
Eleonora's falcon. Curr Zool. 2015;61(3):428-34. https://doi.org/10.1093/ czoolo/61.3.428

34. Kassara C, Gangoso L, Mellone U, Piasevoli G, Hadjikyriakou TG, Tsiopelas N, et al. Current and future suitability of wintering grounds for a long-distance migratory raptor. Sci Rep. 2017;7(1):8798. https://doi.org/10.1038/s41598-01 7-08753-w.

35. Bouten W, Baaij EW, Shamoun-Baranes J, Camphuysen KCJ. A flexible GPS tracking system for studying bird behaviour at multiple scales. J Ornithol. 2013;154(2):571-80. https://doi.org/10.1007/s10336-012-0908-1.

36. Gangoso L, Viana DS, Dokter AM, Shamoun-Baranes J, Figuerola J, Barbosa SA, et al. Cascading effects of climate variability on the breeding success of an edge population of an apex predator. J Anim Ecol. 2020;89(11):2631-43. https://doi.org/10.1111/1365-2656.13304.

37. Gangoso L, Figuerola J. Breeding success but not mate choice is phenotype- and context-dependent in a color polymorphic raptor. Behav Ecol. 2019;30(3):763-9. https://doi.org/10.1093/beheco/arz013.

38. Kenward R. A manual for wildlife radio tagging. London: Academic Press; 2004

39. Mellone U, López-López P, Limiñana R, Urios V. Summer pre-breeding movements of eleonora's falcon falco eleonorae revealed by satellite telemetry: implications for conservation. Bird Conserv Int. 2013;23(4):487-94. https://doi.org/10.1017/S0959270913000051.

40. Lindström $\AA$, Alerstam T, Hedenström A. Faster fuelling is the key to faster migration. Nat Clim Chang. 2019;9(4):288-9. https://doi.org/10.1038/s41558019-0443-7.

41. Shamoun-Baranes J, Bouten W, van Loon EE. Integrating meteorology into research on migration. Integr Comp Biol. 2010;50(3):280-92. https://doi. org/10.1093/icb/icq011.

42. Olson DM, Dinerstein E, Wikramanayake ED, Burgess ND, Powell GVN, Underwood EC, et al. Terrestrial Ecoregions of the world: a new map of life on earth. Bioscience. 2001;51:933.

43. Schaaf C, Wang Z. MCD43A4 MODIS/Terra+Aqua BRDF/Albedo Nadir BRDF adjusted ref daily L3 global - 500m V006. NASA EOSDIS Land Processes DAAC.; 2015.

44. Gorelick N, Hancher M, Dixon M, Ilyushchenko S, Thau D, Moore R. Google earth engine: planetary-scale geospatial analysis for everyone. Remote Sens Environ. 2017;202:18-27. Available from: https://www.sciencedirect.com/ science/article/pii/S0034425717302900. https://doi.org/10.1016/j.rse.2017.06. 031.

45. Kemp MU, Emiel van Loon E, Shamoun-Baranes J, Bouten W. RNCEP: global weather and climate data at your fingertips. Methods Ecol Evol. 2012;3(1): 65-70. https://doi.org/10.1111/j.2041-210X.2011.00138.x

46. Kalnay E, Kanamitsu M, Kistler R, Collins W, Deaven D, Gandin L, et al. The NCEP/NCAR 40-year reanalysis project. Bull Amer Meteor Soc. 1996;77(3): 437-70. https://doi.org/10.1175/1520-0477(1996)077<0437:TNYRP>2.0.CO;2.

47. Hijmans RJ, Williams E, Vennes C. Geosphere: Spherical Trigonometry. R package version 1.5-10; 2019.

48. Chapman JW, Klaassen RHG, Drake VA, Fossette S, Hays GC, Metcalfe JD, et al. Animal orientation strategies for movement in flows. Curr Biol. 2011; 21:R861-70

49. Zhang D. Rsq: R-Squared and Related Measures. R package; 2020.

50. Kuznetsova A, Brockhoff PB, Christensen RHB. Imertest package: tests in linear mixed effects models. J Stat Softw. 2017:82:1-26.

51. R Core Development team. R: a language and environment for statistical computing. Vienna: R Foundation for Statistical Computing; 2019. Available from: http://www.r-project.org/

52. Wickham H. ggplot2: elegant graphics for data analysis. New York: Springer; 2009. https://doi.org/10.1007/978-0-387-98141-3.

53. Carneiro C, Gunnarsson TG, Alves JA. Faster migration in autumn than in spring: seasonal migration patterns and non-breeding distribution of Icelandic Whimbrels Numenius phaeopus islandicus. J Avian Biol. 2018;50. https://doi.org/10.1111/jav.01938.

54. Vansteelant WMG, Klaassen RHG, Strandberg R, Janssens $K$, T'Jollyn $F$, Bouten W, et al. Western Marsh Harriers Circus aeruginosus from nearby breeding areas migrate along comparable loops, but on contrasting schedules in the west African-Eurasian flyway. J Ornithol. 2020;161(4):95365. https://doi.org/10.1007/s10336-020-01785-6.

55. Nilsson C, Klaassen RHG, Alerstam T. Differences in speed and duration of bird migration between spring and autumn. Am Nat. 2013;181(6):837-45. https://doi.org/10.1086/670335. 
56. Klaassen RHG, Strandberg R, Hake M, Alerstam T. Flexibility in daily travel routines causes regional variation in bird migration speed. Behav Ecol Sociobiol. 2008;62(9):1427-32. https://doi.org/10.1007/s00265-008-0572-x.

57. Strandberg R, Klaassen RHG, Olofsson P, Alerstam T. Daily travel schedules of adult Eurasian hobbies Falco subbuteo - variability in flight hours and migration speed along the route. Ardea. 2009;97(3):287-95. https://doi.org/1 0.5253/078.097.0304

58. Thorup K, Alerstam T, Hake M, Kjellén N. Travelling or stopping of migrating birds in relation to wind: an illustration for the osprey. Behav Ecol. 2006; 17(3):497-502. https://doi.org/10.1093/beheco/arj054.

59. Vansteelant WMG, Bouten W, Klaassen RHG, Koks BJ, Schlaich AE, van Diermen J, et al. Regional and seasonal flight speeds of soaring migrants and the role of weather conditions at hourly and daily scales. J Avian Biol. 2015;46(1):25-39. https://doi.org/10.1111/jav.00457.

60. Strandberg R, Klaassen RHG, Hake M, Olofsson P, Alerstam T. Converging migration routes of Eurasian hobbies Falco subbuteo crossing the African equatorial rain forest. Proc Biol Sci. 2009;276:727-33.

61. Briedis M, Bauer S, Adamík P, Alves JA, Costa JS, Emmenegger T, et al. Broad-scale patterns of the afro-Palaearctic landbird migration. Glob Ecol Biogeogr. 2020;29(4):722-35. https://doi.org/10.1111/geb.13063.

62. Tøttrup AP, RHG K, Kristensen MW, Strandberg R, Vardanis Y, Lindström $\AA$, et al. Drought in Africa caused delayed arrival of European songbirds. Science. 2012;338:1307.

63. Walter $\mathrm{H}$. Eleonora's falcon. Adaptations to prey and habitat in a social raptor. Chicago: University of Chicago Press; 1979.

64. Tierney JE, Ummenhofer CC, DeMenocal PB. Past and future rainfall in the horn of Africa. Sci Adv. 2015;1 (9):e1500682. https://doi.org/10.1126/sciadv.1 500682.

65. Bekele-Biratu E, Thiaw WM, Korecha D. Sub-seasonal variability of the Belg rains in Ethiopia. Int J Climatol. 2018;38(7):2940-53. https://doi.org/10.1002/ joc.5474.

66. Camberlin $\mathrm{P}$, Philippon $\mathrm{N}$. The east African march-may rainy season: associated atmospheric dynamics and predictability over the 1968-97 period. J Clim. 2002;15(9):1002-19. https://doi.org/10.1175/1520-0442(2002 015<1002:TEAMMR>2.0.CO;2

67. Vansteelant WMG, Kekkonen J, Byholm P. Wind conditions and geography shape the first outbound migration of juvenile honey buzzards and their distribution across sub-Saharan Africa. Proc R Soc B Biol Sci. 2017;284(1855): 20170387. https://doi.org/10.1098/rspb.2017.0387.

68. Sergio F, Tanferna A, De Stephanis R, López Jiménez L, Blas J, Tavecchia G, et al. Individual improvements and selective mortality shape lifelong migratory performance. Nature. 2014;515(7527):410-3. https://doi.org/10.103 8/nature13696.

69. Campioni L, Dias MP, Granadeiro JP, Catry P. An ontogenetic perspective on migratory strategy of a long-lived pelagic seabird: timings and destinations change progressively during maturation. J Anim Ecol. 2019. https://doi.org/1 0.1111/1365-2656.13044.

70. Wynn J, Collet J, Prudor A, Corbeau A, Padget O, Guilford T, et al. Young frigatebirds learn how to compensate for wind drift. Proc R Soc B Biol Sci. 2020;287:1937.

\section{Publisher's Note}

Springer Nature remains neutral with regard to jurisdictional claims in published maps and institutional affiliations.

Ready to submit your research? Choose BMC and benefit from:
- fast, convenient online submission
- thorough peer review by experienced researchers in your field
- rapid publication on acceptance
- support for research data, including large and complex data types
- gold Open Access which fosters wider collaboration and increased citations
- maximum visibility for your research: over 100M website views per year
At BMC, research is always in progress.
Learn more biomedcentral.com/submissions

